\title{
Characterization of the Cyclic Behavior of Dry Masonry Joints
}

\author{
Paulo B. Lourenço ${ }^{1}$ and Luís F. Ramos ${ }^{2}$
}

\section{Abstract}

Dry masonry mechanics received little attention from research community, when compared with resources invested in traditional (mortar joint) masonry. Nevertheless, a large number of historical stone constructions use dry masonry joints, while, in constructions originally built with weak lime mortar, mortar deterioration leads to a behavior similar to dry masonry. Therefore, the objective of this paper is to contribute to the knowledge of the behavior of dry masonry joints under cyclic loading, which is a key aspect for seismic actions.

The work focuses on the characterization of Coulomb failure criterion and the load-displacement behavior of dry masonry joints under cyclic loading, including aspects as surface roughness, dilatancy and inelastic behavior. A displacement controlled test set-up using masonry couplets is used for this purpose. Besides providing a basis for understanding the behavior of masonry joints in tension, the experiments contribute also to the definition and parameterization of advanced non-linear numeric models.

\section{Keywords:}

Masonry; Testing; Coulomb failure criterion; Dilatancy; Hysteresis; Cyclic loading

\section{Introduction}

There is an important legacy of significant ancient constructions originally built with dry joint masonry, including the majority of the built stone heritage in the Near East, most blocky structures in Greece (such as the Parthenon), several Roman monuments (such as the famous Aqueduct in Segovia, Spain, or the Pont du Gard, France) or certain Medieval monasteries built in the south of Europe. On the other hand, several ancient constructions built with

\footnotetext{
${ }^{1}$ Associate Professor of Civil Engineering, University of Minho, Azurém, P - 4800-058 Guimarães, Portugal, pbl@ civil.uminho.pt

${ }^{2}$ Research Assistant, University of Minho, Azurém, P - 4800-058 Guimarães, Portugal, ramos@ civil.uminho.pt
} 
mortar joints, have experienced a significant loss of mortar due to environmental erosion and have become mechanically similar to constructions originally built with dry joints.

Preserving ancient monuments made of dry-joint masonry (as well as those having lost part of its mortar) requires some knowledge about the mechanics of this particular type of fabric. However, research on structural masonry has been almost exclusively devoted to the characterization of the response of brick / block masonry and, in some cases, stone block masonry, with mortar joints.

Recently, a comprehensive numerical and experimental research project for the characterization of dry stone masonry was initiated, see Oliveira (2003), involving University of Minho and Universitat Politècnica de Catalunya, Barcelona. The present paper aims at contributing to improve the knowledge of dry joint masonry under cyclic shear loading, which is of crucial importance for seismic actions. For this purpose, specimens made of sandstone, named "Montjuic" stone and used in the construction of the historical buildings of Catalonia, Spain, have been tested under increasing vertical stress level. The testing equipment is able to follow the complete stress-displacement diagram, which allows for a full characterization of the most relevant features of friction. Additionally, the stone surface was treated with three different mechanical techniques so that polished, sawn and rough surfaces could be obtained.

\section{On the behavior of masonry joints}

The failure behavior of masonry joints under shear, with moderate pre-compression levels, can be represented by the Coulomb friction law, which establishes a linear relationship between the shear stress $\tau$ and the normal stress $\sigma$, being given by:

$$
\tau=c+\tan \phi \cdot \sigma
$$

Here, $c$ represents the cohesion, which in the case of dry masonry joints assumes the value zero, and $\tan \phi$ is the tangent of the friction angle of the contact surface. The graphical representation of this failure criterion can be visualized in the branch $a$ of Figure 1a. For higher normal compressive stresses, the validity of the Coulomb failure is lost and crushing / shearing of the units, accompanied by diagonal cracking is found (branch $b$ of Figure 1a). In this case, a cap model can be adopted to represent failure of the combined joint - unit ensemble, see for example Lourenço and Rots (1997).

Another relevant feature of masonry joints is the so-called dilatancy angle $\psi$, which measures the volume change upon shearing. The ratio between the normal displacement $u_{n}$ (see Figure 1b) and the shear displacement $u_{s}$ 
gives $\tan \psi$, which can assume positive or negative values. Usually, the dilatancy angle is positive but tends to zero upon increasing shear displacement and increasing normal confining stress, see van der Pluijm (1999).

For the purpose of characterizing the Coulomb failure criterion, different test methods to determine the strength parameters $c, \tan \phi$ and the volume parameter $\tan \psi$ have been adopted by researchers (e.g. Copeland and Saxer, 1964; Smith and Carter, 1971; Sinha and Hendry, 1975; Hamid et al., 1979; Hofmann and Stockl, 1986; Atkinson et al. 1989; and van der Pluijm, 1993), see Figure 2.

All test methods fail to reproduce an absolutely uniform distribution of the normal and shear stresses even if the triplet test has been adopted as the standard test in Europe, CEN (1995). Nevertheless, efforts have been made for minimizing the undesired effects associated with the appearance of bending, which is responsible for the variations of normal stresses in the joint, see Riddington et al. (1997) for a comprehensive discussion.

Here, the testing method adopted is the couplet test, with clamping devices such that the test set-up becomes rather similar to the well-known shear boxes.

\section{Description of the Testing Procedures}

The sandstone adopted for the tests is a sedimentary homogeneous stone with a soft texture and small grains (dimensions between 40 and $650 \mu \mathrm{m}$ ). The mechanical properties of this stone have been studied in detail by Oliveira (2000), which indicated a Young's modulus of $18800 \mathrm{~N} / \mathrm{mm}^{2}$, a Poisson's ratio of 0.3 and a strength of $91.6 \mathrm{~N} / \mathrm{mm}^{2}$. For the current research program, the material was delivered in prisms with $200 \times 200 \times 100 \mathrm{~mm}^{3}$. The prisms were sawn according to the layout illustrated in Figure 3, meaning that the final dimensions of the stone units were $80 \times 50 \times 40 \mathrm{~mm}^{3}$. The material tested was obtained from different stones so that the variability of the material could be evaluated.

The tests were carried out in a specially developed CS 7400-S - Shear Testing System - from James Cox, (see Figure 4a), which features two independent actuators: a vertical actuator associated with the normal stress and a horizontal actuator associated with the shear stress. Each actuator has a maximum load capacity of $\pm 20 \mathrm{kN}$, both in tension and compression. Besides the internal displacement transducers of each actuator, three Linear Variable Displacement Transducers (LVDTs) were located at the face of the specimens (see Figure 4b). The LVDTs used had a range of $0.5 \mathrm{~mm}$, with a sensitivity of $240 \mathrm{mV} . \mathrm{N} / \mathrm{mm}$ and a linearity of $0.25 \%$ for the maximum displacement. 
The vertical actuator was force controlled with the force $F_{n}$ shown in Figure 5a, so that the vertical stress was kept constant and equal to three compressive normal stress levels $\left(0.5,1.0\right.$ and $\left.1.5 \mathrm{~N} / \mathrm{mm}^{2}\right)$. After the application of this confining stress, the horizontal displacement $\delta_{n}$ was applied at a constant rate of $\pm 2.5 \mu \mathrm{m} / \mathrm{s}$, see Figure $5 \mathrm{a}$. It is noted that, as the vertical force was kept constant, the specimens could move in the vertical direction due to dilatancy effects.

The tests specimens were placed in circular steel platens that were clamped to the actuators, as seen in Figure $5 \mathrm{~b}$, so that rotations of the platens were not allowed. The specimens are made of two independent stone units and, therefore, each single unit was fixed to one steel platen, using additional clamps. These clamps consisted of two rectangular steel prisms with a size of $30 \times 35 \times 90 \mathrm{~mm}^{3}$, fastened to the steel platens with two bolts. It is noted that one of the clamps was provided with oval openings in order to allow for adequate adjustment of the stone unit to the platen.

The contact of the clamps with the stone units was made using two neoprene shims, with a size of $15 \times 3 \times 50 \mathrm{~mm}^{3}$, see Figure 5b. In addition, two Teflon layers, with $115 \mu \mathrm{m}$ of thickness and lubricated with fine oil, were placed between the stone units and the steel platens. These procedures aim at minimizing the bending effects associated with shear loading. The usage of the neoprene shims ensures that the shear load is applied in the neighborhood of the joint and the usage of Teflon layers ensures that no friction is present between the stone units and the platens, which is of relevance for load-reversal. Nevertheless, due to the displacement inversion during testing, a small pre-compression of the stone units along the horizontal direction has been applied. It is pointed out that this horizontal confining force $P$, see Figure 5a, introduced by the steel clamps produces only minor effects in the joints, which is the part to be analyzed in the present paper. The value of the force $P$, measured with a dynamometer, is around $4000 \mathrm{~N}$.

The process for preparation of the specimens can be described as follows:

- Teflon layers were pre-placed on the machine platens;

- A layer of epoxy resin (DEVCON) was applied between the stone unit and the Teflon contacting layer. The thickness of this layer was $3 \mathrm{~mm}$ and the objective was to ensure perfectly leveled surfaces, even if the stone units had been properly sawn and ground in the face contacting the Teflon layers;

- The rubber shims were placed close to the edges of the stone units and the prisms were confined with the clamps;

- Both platens were clamped and the pre-compression was applied and kept constant for approximately one hour, so that the epoxy resin could be perfectly leveled. 


\subsection{Numerical Validation of the Test Set-up}

To validate the test set-up, a finite element model was built, including eight-noded continuum elements to represent the steel clamps, the neoprene shims and the stone units, and six-noded zero thickness interface elements to represent the joint. The inelastic behavior of the interface has been modeled at this evaluation stage using an idealplastic Coulomb friction law, with zero cohesion and a friction angle given by tan $\phi$ equal to 0.75 .

Figure 6 clearly indicates that the distribution of stresses is non-uniform, both before and after sliding, with a concentration of stresses near the edges, due to the bending effect and the neoprene shims. Figure 7a presents the stress distribution in the joint just before sliding. This confirms the existence of peaks in the normal stresses near the edges of the joint, due to the shims, and of zero shear stresses near the edges of the joint, due to equilibrium requirements. The average of the normal stresses equals $1.0 \mathrm{~N} / \mathrm{mm}^{2}$ (with a maximum of $+43 \%$ and a minimum of $-9 \%$ ), which is the prescribed value. The filled square in the diagrams indicates the first integration point to reach the failure criterion, which is associated with large shear stress and moderate normal stress. As it can be seen in Figure 7b, several integration points of the joint are distant from the adopted Coulomb failure criterion. Actually, the average shear stress value at this stage is $0.57 \mathrm{~N} / \mathrm{mm}^{2}$, which is far below the expected maximum of the failure criterion equal to $\tan \phi \times \sigma$ $\left(0.75 \mathrm{~N} / \mathrm{mm}^{2}\right)$.

Figure 8a presents the stress distribution in the joint at ultimate stage (maximum load) for monotonic loading. Again, the obtained distribution is non-uniform but a considerable change in the value of the shear stresses occurred. It can be observed that the peaks of the normal stresses are perfectly correlated with the peaks of the shear stresses, as it should be expected due to the Coulomb failure criterion. Figure $8 \mathrm{~b}$ indicates that all the integration points are aligned with the failure criterion, but with different normal stress levels. The average normal stress value stays equal to $1.0 \mathrm{~N} / \mathrm{mm}^{2}$, with a peak value of $1.43 \mathrm{~N} / \mathrm{mm}^{2}$. The average shear stress is equal to $0.75 \mathrm{~N} / \mathrm{mm}^{2}$. This means that the ratio between the shear and normal average stresses is equal to the value adopted for input of the failure criterion, i.e. $\tan \phi=0.75$, which allows concluding that the proposed test set-up is adequate for the purpose of identifying the mechanical data for the Coulomb failure criterion.

It is also noted that the distribution of the normal and the shear stresses is almost constant for more than $60 \%$ of the length of the joint. 


\section{Obtained Experimental Results}

This study regarding the behavior of dry joints contemplated three different types of treatments for the stone surface, namely: (a) polished surface using sandpaper number 180 (specimens denoted as $\mathrm{P}$ series); (b) mechanically sawn surface (specimens denoted as S series); and (c) artificially rough surface using a mechanically random spike (specimens denoted as R series). With the proposed approach it is possible to compare the influence of the stone surface roughness in the behavior of the dry joints. Here, only the most relevant experimental results are addressed and the reader is referred to Ramos (2002) for a complete description.

As stated before, the key mechanical parameter of the dry joints is $\tan \phi$, which can be obtained by linear regression from tests with different normal confining stresses. Here, three levels of normal stress have been considered, namely $0.5,1.0$ and $1.5 \mathrm{~N} / \mathrm{mm}^{2}$. For each stress level and each surface treatment, three identical specimens have been tested, making a total of twenty-seven specimens.

The tests were carried out under displacement control, using the horizontal LVDT positioned in the direction of the shear load (see Figure 4b). The histogram of imposed horizontal displacements was defined according to the surface treatment, from preliminary tests (see Figure 9 for a typical histogram). From the behavior observed in the preliminary tests, the following loading cycles have been adopted: (a) P series - six loading cycles with $\pm 0.1 / \pm 0.2 / \pm 0.3 / \pm 0.4$ / \pm 0.4 / $\pm 0.4 \mathrm{~mm}$; (b) S series - four loading cycles with $\pm 0.1 / \pm 0.2 / \pm 0.3$ / $\pm 0.4 \mathrm{~mm}$; (b) $\mathrm{R}$ series - seven loading cycles with $\pm 0.1 / \pm 0.2 / \pm 0.3 / \pm 0.4 / \pm 0.8 / \pm 1.2 / \pm 1.6 \mathrm{~mm}$

\subsection{Load-displacement Diagrams}

The typical behavior of the specimens for series $\mathrm{P}$ (polished surface) is given in Figure 10. It can be observed that the elastic behavior is followed by fully plastic behavior, as no recover of the joint deformation occurred upon load removal. The (small) shear strength increase with plastic deformation and the (considerable) shear strength increase with the loading cycles was somewhat unexpected. This behavior occurred for all specimens, independently of the level of vertical confining stress.

It is believed that the increase of the shear strength can be justified by the roughness increase of the stone surface upon shearing and, consequent, wearing of the joint. After completing the loading / unloading cycles, wearing of the stone surface was encountered in all specimens. 
In this series, the number of sampling points in the elastic loading and unloading branches is minimal, which indicates an almost rigid-plastic behavior of the joints.

The typical behavior of the specimens for series $\mathrm{S}$ (sawn surface) is given in Figure 11. For this series, the presence of a non-linear branch in the pre-sliding phase is clearly visible. This non-linear branch, which indicates progressive sliding of the joint and simulates stiffness degradation of the dry joints, is not found in the unloading branches. It is also observed that the shear strength remains constant with an increasing number of loading cycles. The slightly lower shear strength for the first cycle indicates that the final displacement of the first cycle was insufficient to reach the maximum shear strength. In the specimens tested with lower vertical confining stress, no difference was found between the shear strength of the first loading branch and the additional cycles.

The typical behavior of the specimens for series $\mathrm{R}$ (rough surface) is given in Figure 12. For this series, the presence of a non-linear branch in the pre-sliding phase is also clearly visible. Again, this non-linear branch is not found in the unloading branches. The shear strength increases during the first three / four cycles but then remains constant with an increasing number of loading cycles. This phenomenon is most likely related to the wearing of the interlocking localized contacts between the rough surfaces. Finally, it is also noted that non-symmetric behavior and hardening during plastic shearing were found, which are attributed to the randomness of contact in the artificially, mechanically produced, rough surface.

\subsection{Coulomb Failure Criteria}

Figure 13 illustrates the failure criteria obtained for the three series of stone specimens, both the initial values (first cycle) and the final values (last cycle). As indicated in the figures, Coulomb friction law fits very well the experiments, with an average linear regression factor $r^{2}$ equal to 0.96 , upon enforcing zero cohesion.

The results in terms of $\tan \phi$ vary significantly according to the surface treatment and upon wearing of the surface, see Table 1. Series P exhibits an extremely low initial friction angle $\left(\tan \phi_{i}=0.18\right)$ due to the smoothness of the surface and a very significant difference between the initial and the final friction angle $\left(\tan \phi_{f} / \tan \phi_{i}=2.4\right)$. Series $S$ exhibits no variation between the initial and final friction angle, which seems just a coincidence related with the particular sandstone and surface treatment, meaning that the sawn surface has a roughness similar to the surface obtained by the wearing process associated with cyclic loading. Finally, series R exhibits an initial friction angle lower 
than series $\mathrm{S}$ but upon wearing the values increase, as expected, to the highest value of all series. Therefore, it seems possible to state that an increase of the surface roughness, results in an increase of the final friction angle.

\subsection{Dilatancy}

The dilatancy angle $\psi$ measured in all series was very low and, for practical purposes, a value of zero is recommended. In fact, for the three series, the value of the $\tan \psi$ was always lower than \pm 0.05 , see Figure 14 a.

Nevertheless, series R exhibits a significant localized reduction of volume, upon load reversal, see Figure 14b, even if inside each cycle the value of the $\tan \psi$ remains very low. This phenomenon, which is again associated with wearing of the contact points between the rough surfaces, does not occur in series $\mathrm{P}$ and $\mathrm{S}$. The value of the total vertical compaction of the specimens was, on the average, equal to $0.4 \mathrm{~mm}$. The rate of compaction decreases with increasing cycles and an "equivalent" dilatancy angle $\psi^{*}$ can be defined as the ratio between vertical compaction and total displacement per cycle. In this case, the initial value for $\tan \psi^{*}$ is equal to -0.3 and a final value is equal to -0.01 , which is equal to zero for practical purposes.

\subsection{Pre-peak Inelastic Behavior}

As referred below, very few points could be recorded in the elastic response of series $\mathrm{P}$, due to the smoothness of the stone surface. For the other two series ( $\mathrm{S}$ and $\mathrm{R}$ ), the variation of stiffness in the pre-peak phase is significant. This variation is illustrated by means of a shear force vs. horizontal displacement diagram in which the elastic horizontal displacement of the stone itself is removed from the total displacement. The joint horizontal displacement $u_{\text {joint }}$ is then given by

$$
u_{\text {joint }}=u_{\text {measured }}-\frac{\tau}{k_{\text {shear }}},
$$

where $u_{\text {measured }}$ is the value read in the LVDT and the shear stiffness $k_{\text {shear }}$ is calculated from the unloading branches, dividing the variation of shear stress $\Delta \tau$ up to zero by the respective variation of the shear displacement $\Delta u_{\text {measured }}$. The values of the shear stiffness obtained are constant through cycles, which indicate linear elastic behavior of the stone. Figure 15 indicates the effect of applying the correction to the load-displacement diagram previously shown in 
Figure 11. It is observed that the unloading branches are vertical, which represents fully plastic behavior of the joint upon load removal, but the reloading branches exhibit gradual inelastic behavior (or hardening behavior). This phenomenon seems to be addressed in the present paper from the first time and would seem unexpected for dry masonry joints. As stated before, the existence of a variable stiffness of the dry joint indicates progressive sliding of the joint and cannot be associated with an elastic (recoverable) continuum deformation.

A comparison between the reloading diagrams indicates that no significant variations in stiffness occur with the increase in the number of cycles. On the contrary, it was observed that the reloading stiffness increases linearly with the applied vertical confining stress, which is related to the microstructure and interlocking of the material in the joint.

The global behavior of all the joints seems to be illustrated adequately using the load-displacement diagram and failure criterion indicated in Figure 16. The branches with the letter $a$ indicate hardening behavior, after which ideal plastic behavior follows (branches indicated by the letter $b$ ). The unloading stage is identified with the letter $c$, which represents full plastic behavior of the joint or, equivalently, infinite unloading stiffness. The changes in the hardening behavior are not significant and, for practical purposes, the different branches $a_{1}, a_{2}, \ldots, a_{\mathrm{f}}$ can be considered equal and independent from the loading cycle. On the contrary, the experimental results indicate that the shape of the hardening branch $a$ depends on the applied normal stress level.

\section{Conclusions}

The paper presents experimental results on the characterization of the shear behavior of dry masonry joints under cyclic loading. The material used in all the tests is Catalonian sandstone, from which blocks cut off and have been prepared with different surface treatments (polished, sawn and rough surfaces). The specimens consist of couplet tests.

The experimental set-up has been designed so that the bending effects associated with shear testing are minimized. The vertical confining pressure is kept constant while the test is carried out under horizontal displacement control. A finite element analysis of the test set-up demonstrated its adequacy to provide the parameters required for the definition of the Coulomb friction law.

The experimental results indicated the Coulomb friction law is adequate to represent the failure of dry masonry joints under moderate stress levels. It has been observed that significant differences can be found between the initial and the final friction angle, after a given number of cycles. The roughness of the surface is a key aspect for the definition of the friction angle of the joint. It has been observed that a larger roughness leads to a larger final friction angle. 
In all cases, almost zero dilatancy has been found during each cycle. For rough surfaces, which seem more in agreement with historical masonry structures, a negative equivalent dilatancy should be taken into account for confined structural elements. This compaction occurs at each load reversal, due to wearing of the contact points in the joints.

It was also shown that advanced non-linear models for the simulation of the hysteretic behavior of dry masonry joints should include a hardening branch in the loading stage. Nevertheless, the shear deformation is fully plastic (or irreversible).

\section{Acknowledgements}

The present work was partially supported by project PRAXIS-C-ECM-13247-1998 funded by Fundação para a Ciência e Tecnologia, Portugal.

\section{Notation}

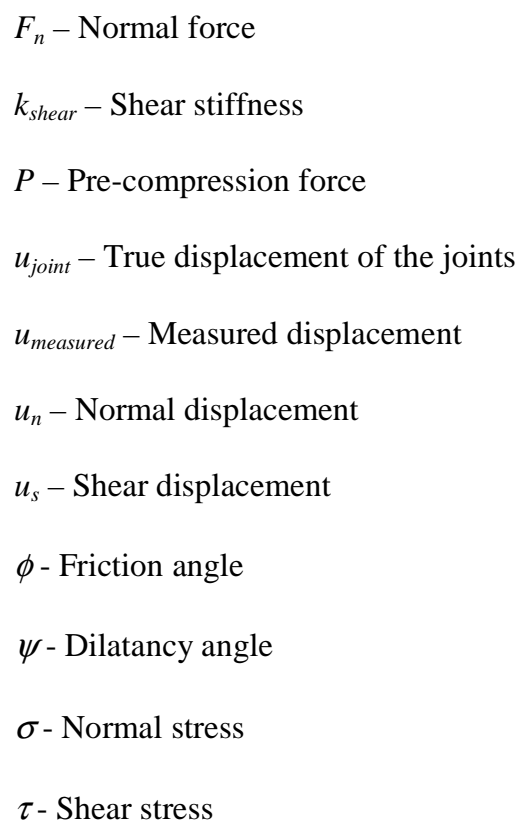

\section{References}

Atkinson, R.H.; Amadei, B.P.; Saeb, S.; Sture, S. (1989). Response of Masonry and Joints in Direct Shear, J. Struct. Engrg, ASCE, 115(9), 2276-2296 
CEN - European Committee for Normalization (1996). Methods of Test for Masonry; Determination of Initial Shear Strength, prEN 1052. Part 3

Copeland, R.E.; Saxer, E.L. (1964). Tests on Structural Bond of Masonry Mortars to Concrete Block, J. Amer. Conc., Inst., 61(11), 1411-1451

Hamid, A.A.; Drysdale, R.G.; Heidebrecht, A.C. (1979). Shear Strength of Concrete Masonry Joints, J. Struct. Div., ASCE, 105, pp. 1227-1240

Hofmann, P.; Stockl, S. (1986). Tests on the Shear-bond Behaviour in the Bed-joints of Masonry, Masonry International, 9, 1-15

Lourenço, P.B., Rots, J.G. (1997). A Multi-surface Interface Model for the Analysis of Masonry Structures, J. Engrg. Mech., ASCE, 123(7), pp. 660-668

Oliveira, D.V. (2003). Experimental and Numerical Analysis of Blocky Masonry Structures Under Cyclic Loading, $\mathrm{PhD}$ Thesis, University of Minho, Portugal

Pluijm, R. van der (1993). Shear Behaviour of Bed Joints, Proc. $6^{\text {th }}$ North American Masonry Conference, Philadelphia, USA, pp.125-136

Pluijm, R. van der (1999). Out of Plane Bending of Masonry Behaviour. PhD Thesis. Eindhoven University of Technology, The Netherlands

Ramos, L.F. (2002). Numerical and Experimental Analysis of Historical Masonry Structures (in Portuguese). MSc Thesis. University of Minho, Portugal

Riddington, J.R.; Fong, K.H.; Jukes, P. (1997). Numerical Study of Failure Initiation in Different Joint Shear Tests, Masonry International, 11(2), 33-64

Sinha, B. P.; Hendry, A. W. (1975). Tensile Strength of Brick Specimens. Proc. Brit. Ceram. Soc., 24, 91-100

Smith, B.S.; Carter, C. (1971). Hypothesis for Shear Failure of Brickwork, J. Struct. Div., ASCE, 97(4), 1055-1062 


\section{List of Tables}

Table 1 - Tangent of the friction angle for the different series 


\section{List of Figures}

Figure 1 - Behavior of dry masonry joints: (a) Failure criterion for low and high compressive stresses, and (b) volume change (dilatancy) upon shearing

Figure 2 - Different types of shear tests: (a) couplet test, (b) van der Pluijm (1999) test and (c) triplet test

Figure 3 - Making of the units from the original stone prisms (dimensions in $\mathrm{mm}$ )

Figure 4 - Test set-up: (a) CS 7400-S testing equipment; and (b) location of the external LVDTs

Figure 5 - Test set-up: (a) force and displacement imposed to the specimen; and (b) details for minimizing bending effects

Figure 6 - Results of the numerical analysis of the test set-up for the stone units, in terms of deformed meshes and vertical stresses: (a) before sliding; and (b) after sliding

Figure 7 - Distribution of stresses in the joint just before sliding: (a) normal and shear stresses; and (b) location of integration points with respect to the Coulomb failure criterion

Figure 8 - Distribution of stresses in the joint after sliding: (a) normal and shear stresses; and (b) location of integration points with respect to the Coulomb failure criterion

Figure 9 - Typical histogram for the prescribed horizontal displacements (series S)

Figure 10 - Typical load-displacement diagram for a pre-confining level of $1.5 \mathrm{~N} / \mathrm{mm} 2$ (Series P)

Figure 11 - Typical load-displacement diagram for a pre-confining level of $1.5 \mathrm{~N} / \mathrm{mm} 2$ (Series $\mathrm{S}$ )

Figure 12 - Typical load-displacement diagram for a pre-confining level of $1.5 \mathrm{~N} / \mathrm{mm} 2$ (Series R)

Figure 13 - Experimental failure criteria for different surface treatments: (a) initial failure criteria; and (b) final failure criteria

Figure 14 - Volume changes: (a) typical variation of the dilatancy angle; and (b) relation between horizontal and vertical displacements for all series

Figure 15 - Typical adjusted load-displacement diagram for the joints of series $\mathrm{S}$ and $\mathrm{R}$

Figure 16 - Typical observed behavior of dry joints: (a) hysteretic diagram; and (b) failure criterion 
Table 1 - Tangent of the friction angle for the different series

\begin{tabular}{|c|c|c|c||}
\hline Series & $\tan \phi_{i}$ & $\tan \phi_{f}$ & $\tan \phi_{i} / \tan \phi_{f}$ \\
\hline \hline $\mathrm{P}$ & 0.18 & 0.43 & 2.4 \\
\hline $\mathrm{S}$ & 0.62 & 0.63 & 1.0 \\
\hline $\mathrm{R}$ & 0.56 & 0.74 & 1.3 \\
\hline
\end{tabular}




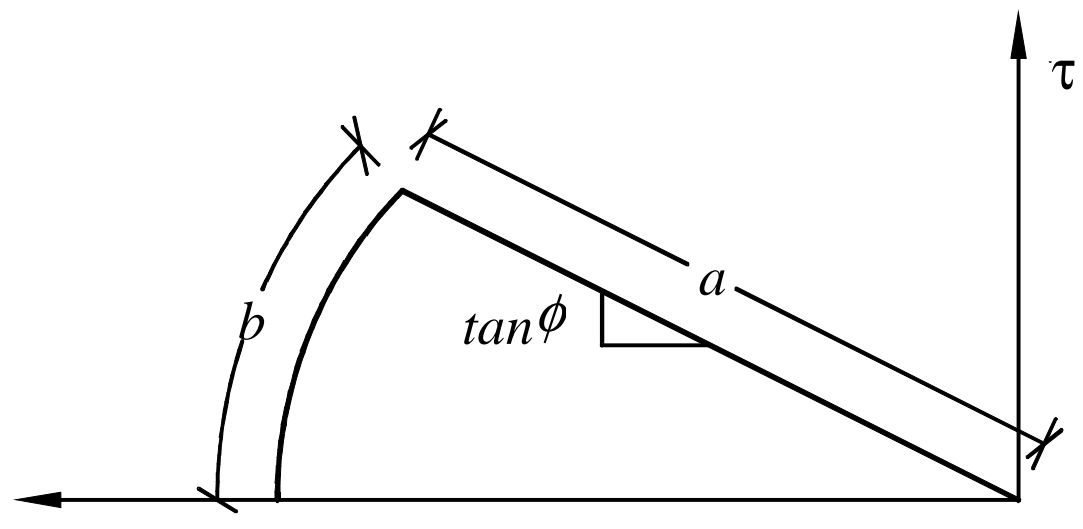

$\sigma$

(a)

Figure 1 - Behavior of dry masonry joints: (a) Failure criterion for low and high compressive stresses, and (b) volume change (dilatancy) upon shearing 


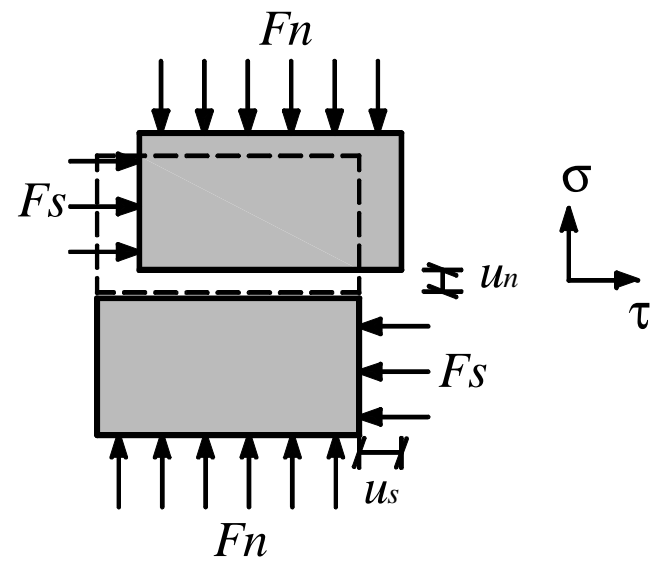

(b)

Figure 1 - Behavior of dry masonry joints: (a) Failure criterion for low and high compressive stresses, and (b) volume change (dilatancy) upon shearing 


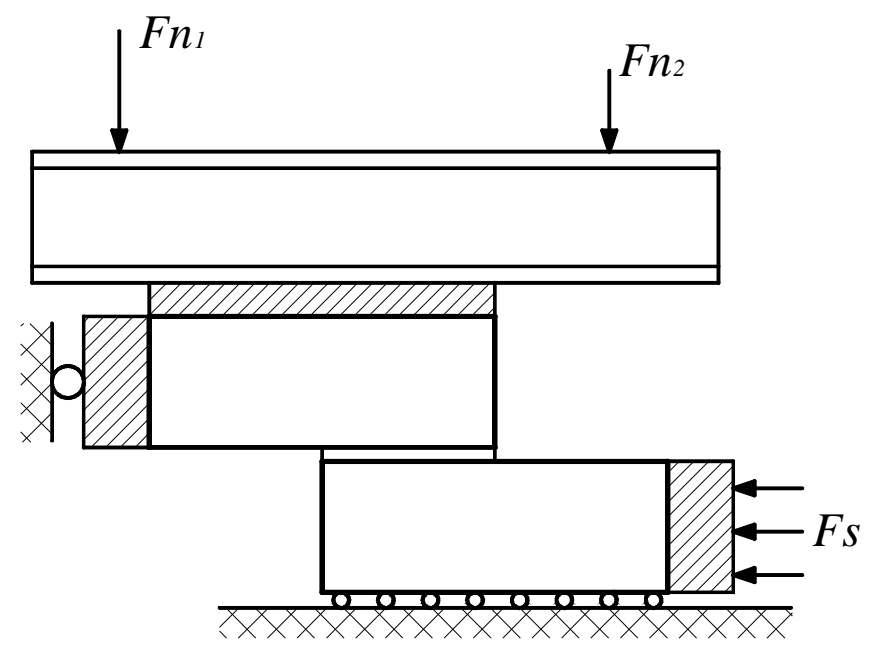

(a)

Figure 2 - Different types of shear tests: (a) couplet test, (b) van der Pluijm (1999) test and (c) triplet test 


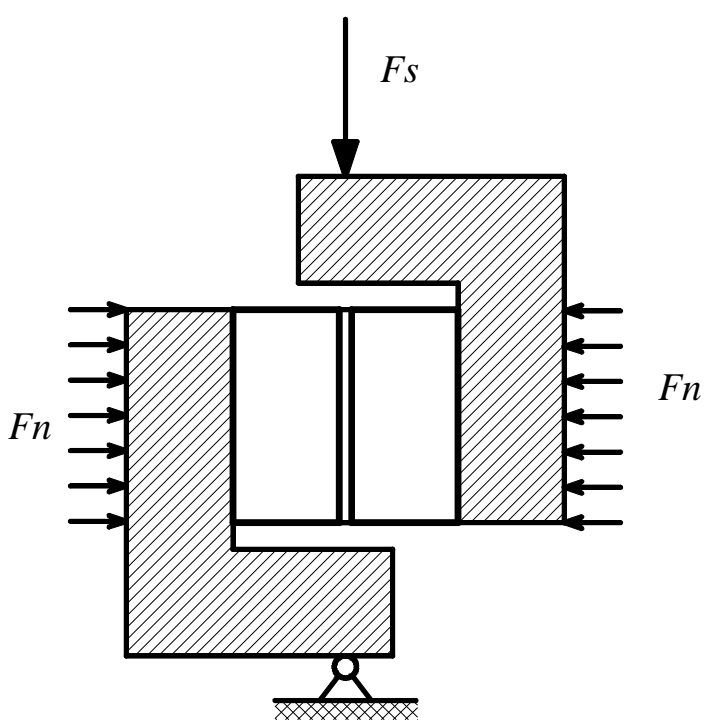

(b)

Figure 2 - Different types of shear tests: (a) couplet test, (b) van der Pluijm (1999) test and (c) triplet test 


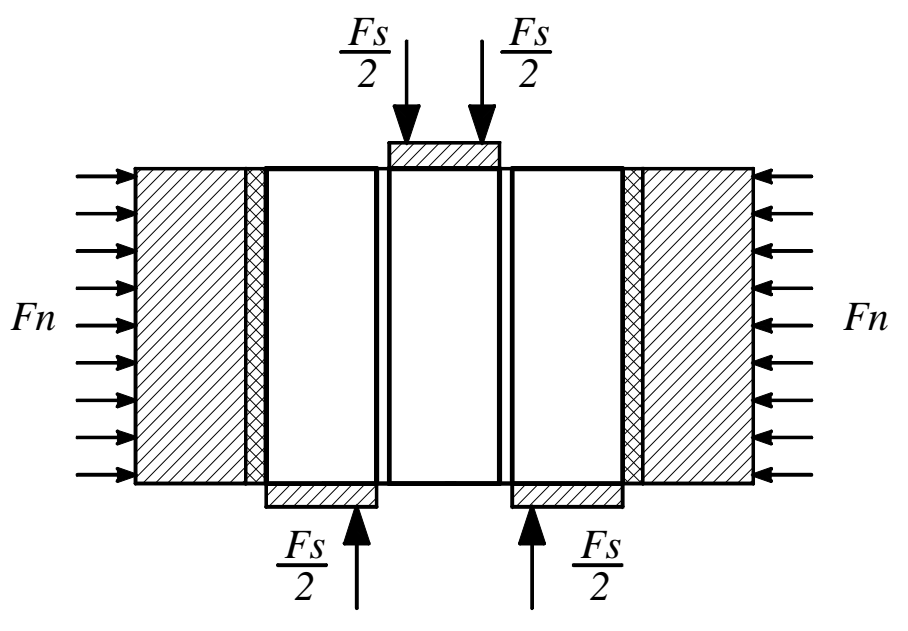

(c)

Figure 2 - Different types of shear tests: (a) couplet test, (b) van der Pluijm (1999) test and (c) triplet test 


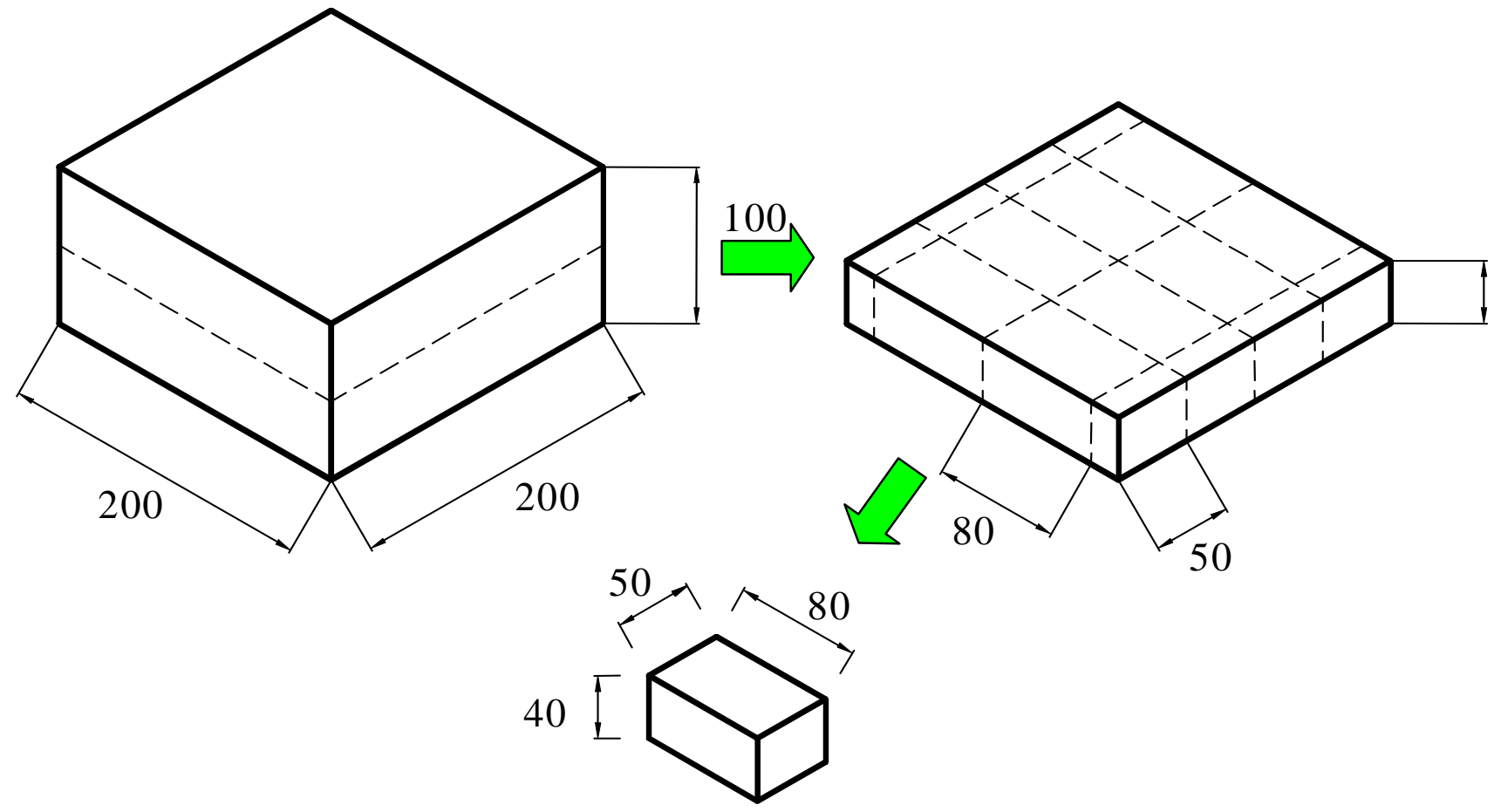

Figure 3 - Making of the units from the original stone prisms (dimensions in $\mathrm{mm}$ ) 


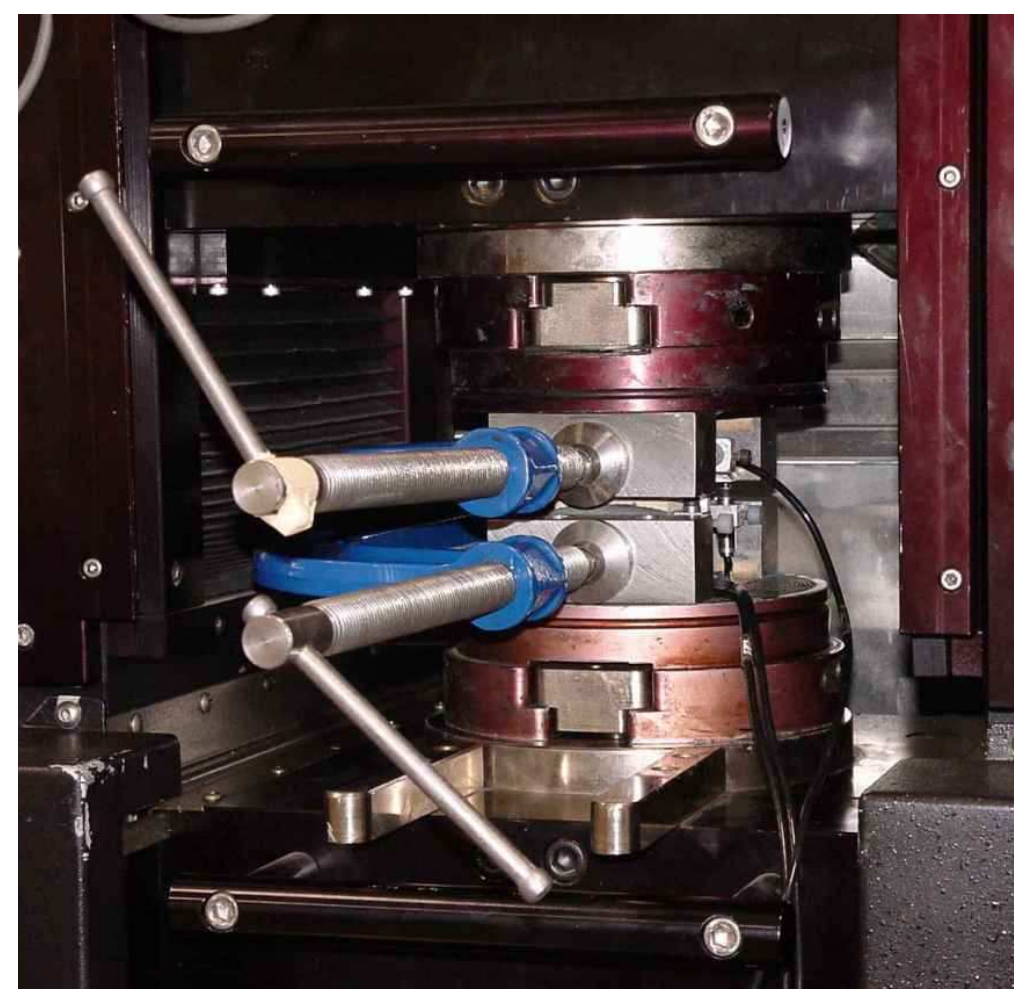

(a)

Figure 4 - Test set-up: (a) CS 7400-S testing equipment; and (b) location of the external LVDTs 


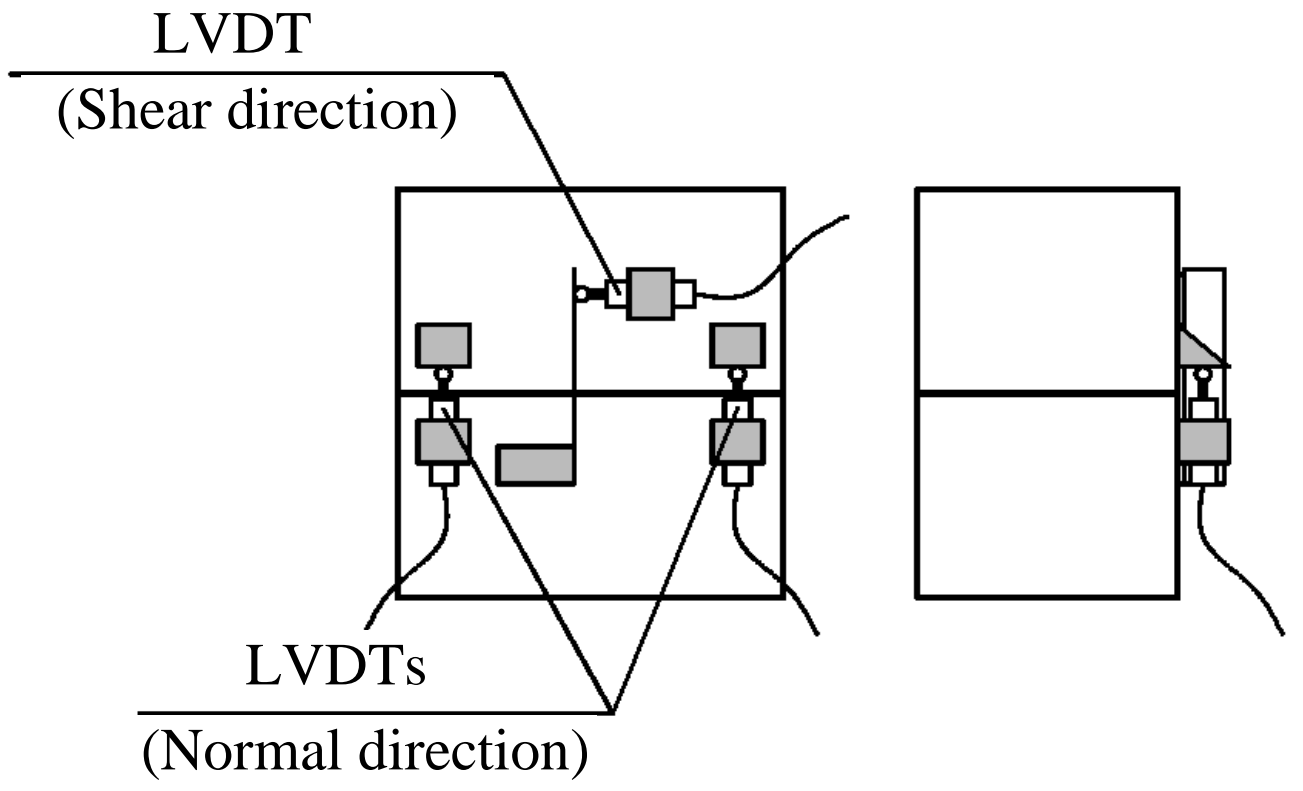

(b)

Figure 4 - Test set-up: (a) CS 7400-S testing equipment; and (b) location of the external LVDTs 


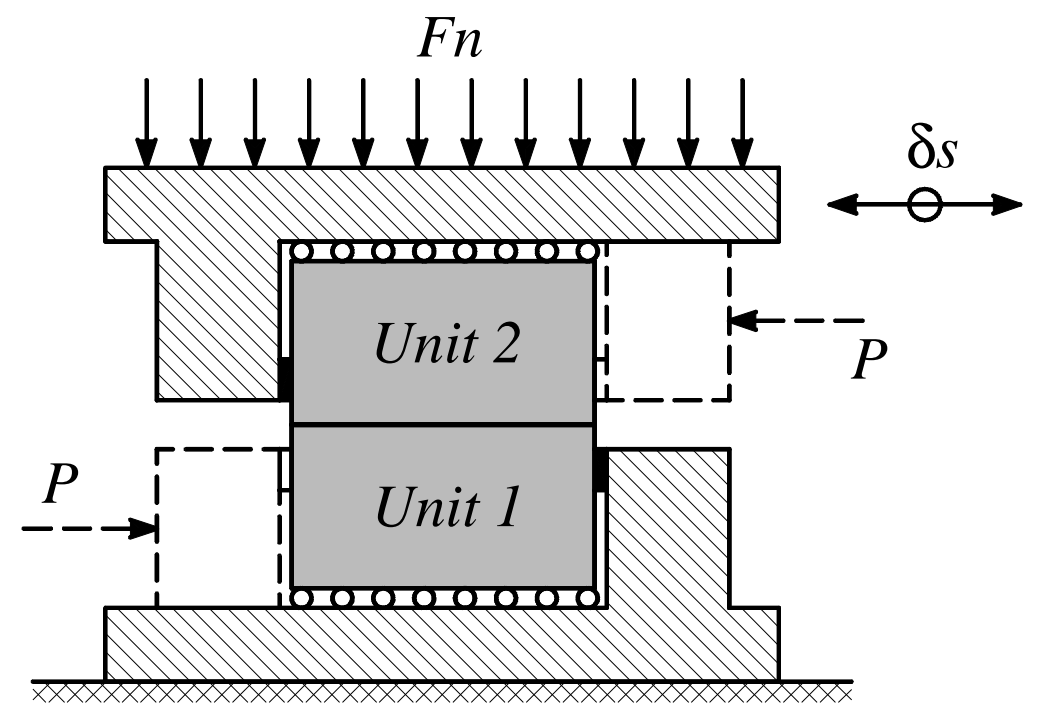

(a)

Figure 5 - Test set-up: (a) force and displacement imposed to the specimen; and (b) details for minimizing bending effects 


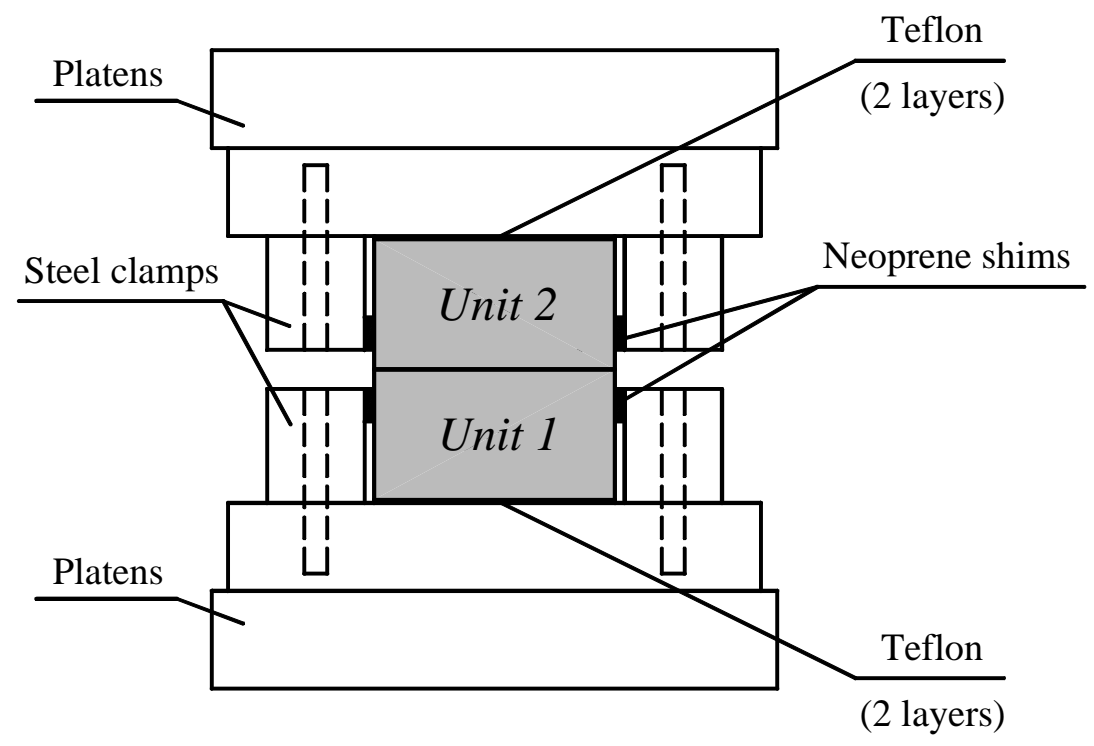

(b)

Figure 5 - Test set-up: (a) force and displacement imposed to the specimen; and (b) details for minimizing bending effects 


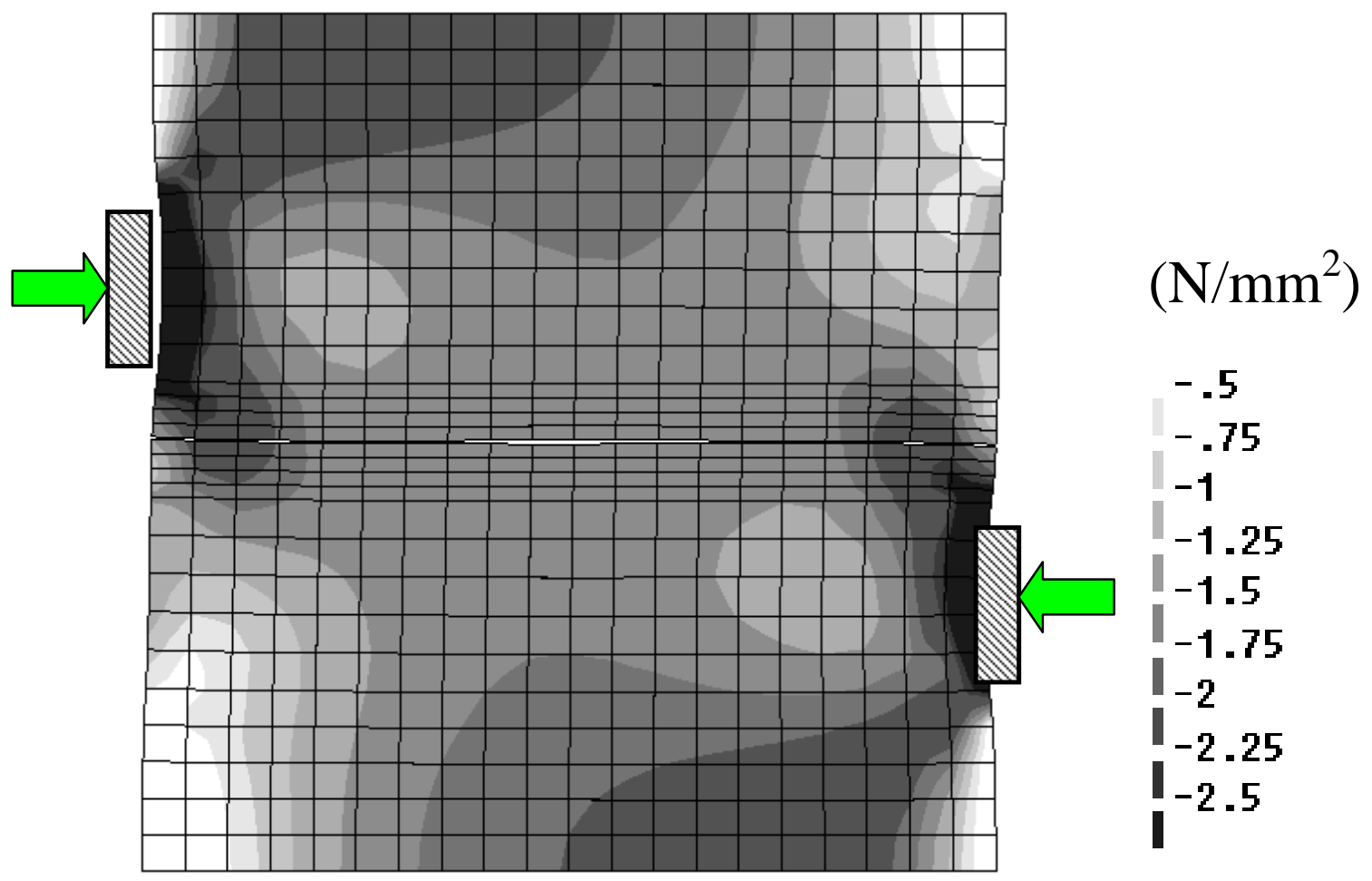

(a)

Figure 6 - Results of the numerical analysis of the test set-up for the stone units, in terms of deformed meshes and vertical stresses: (a) before sliding; and (b) after sliding 


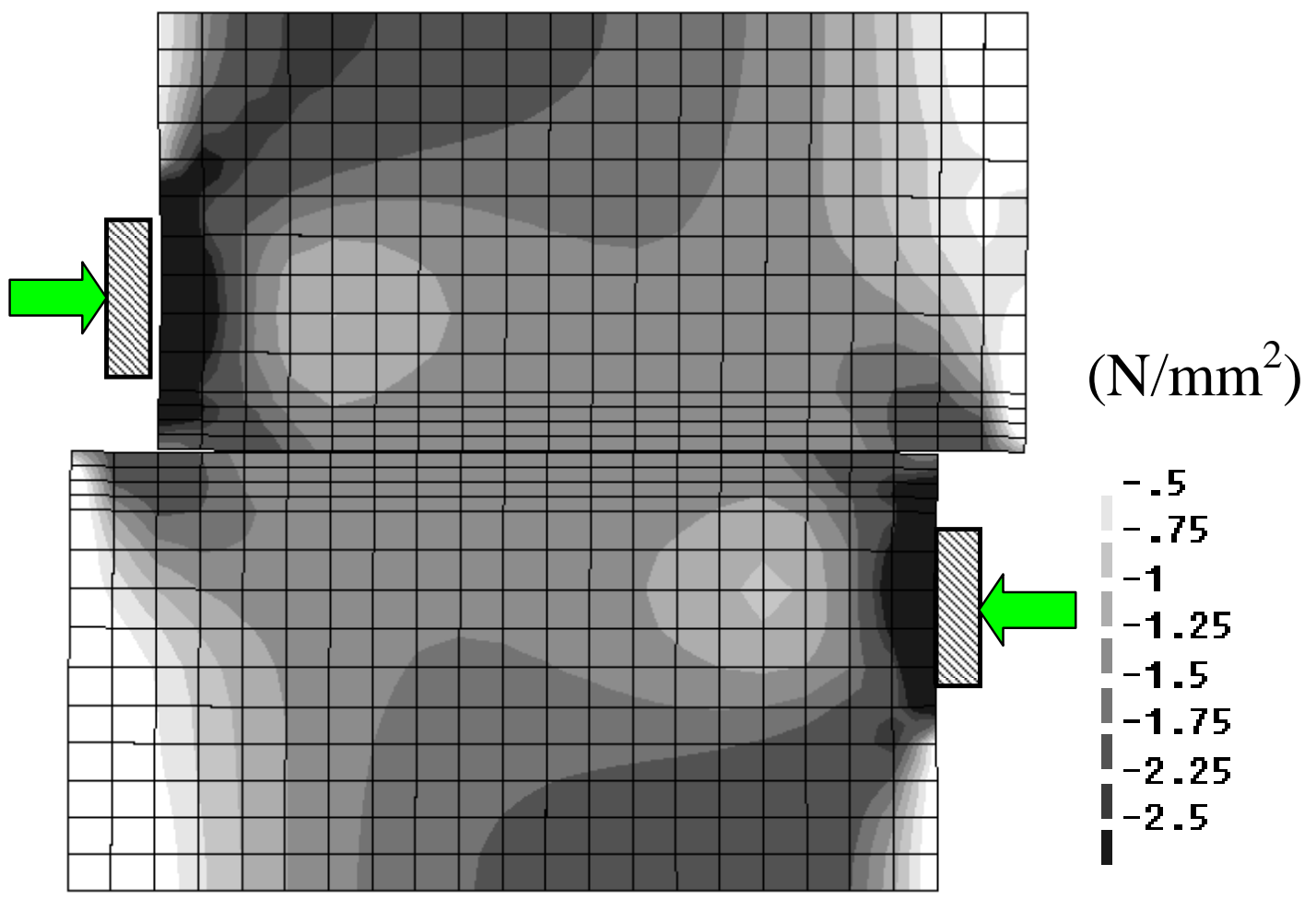

(b)

Figure 6-Results of the numerical analysis of the test set-up for the stone units, in terms of deformed meshes and vertical stresses: (a) before sliding; and (b) after sliding 


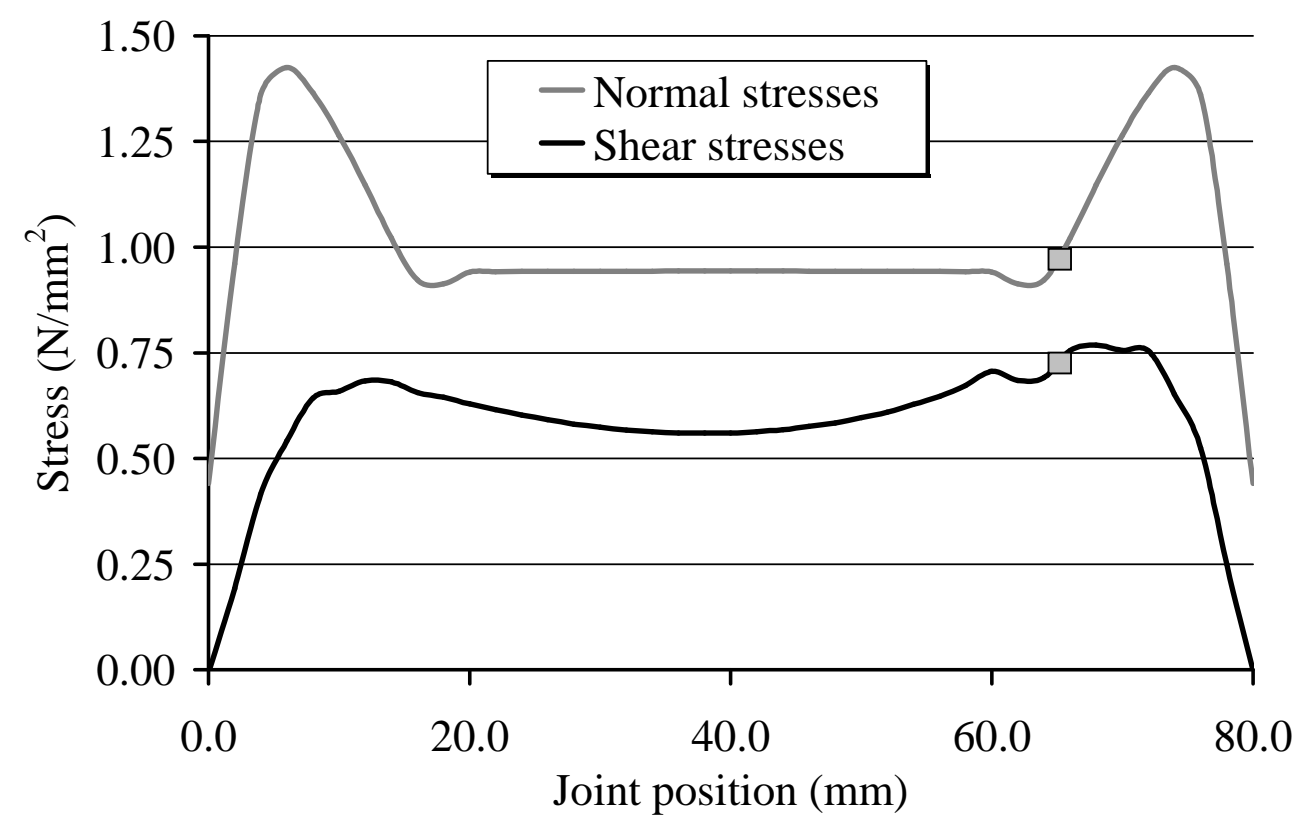

(a)

Figure 7 - Distribution of stresses in the joint just before sliding: (a) normal and shear stresses; and (b) location of integration points with respect to the Coulomb failure criterion 


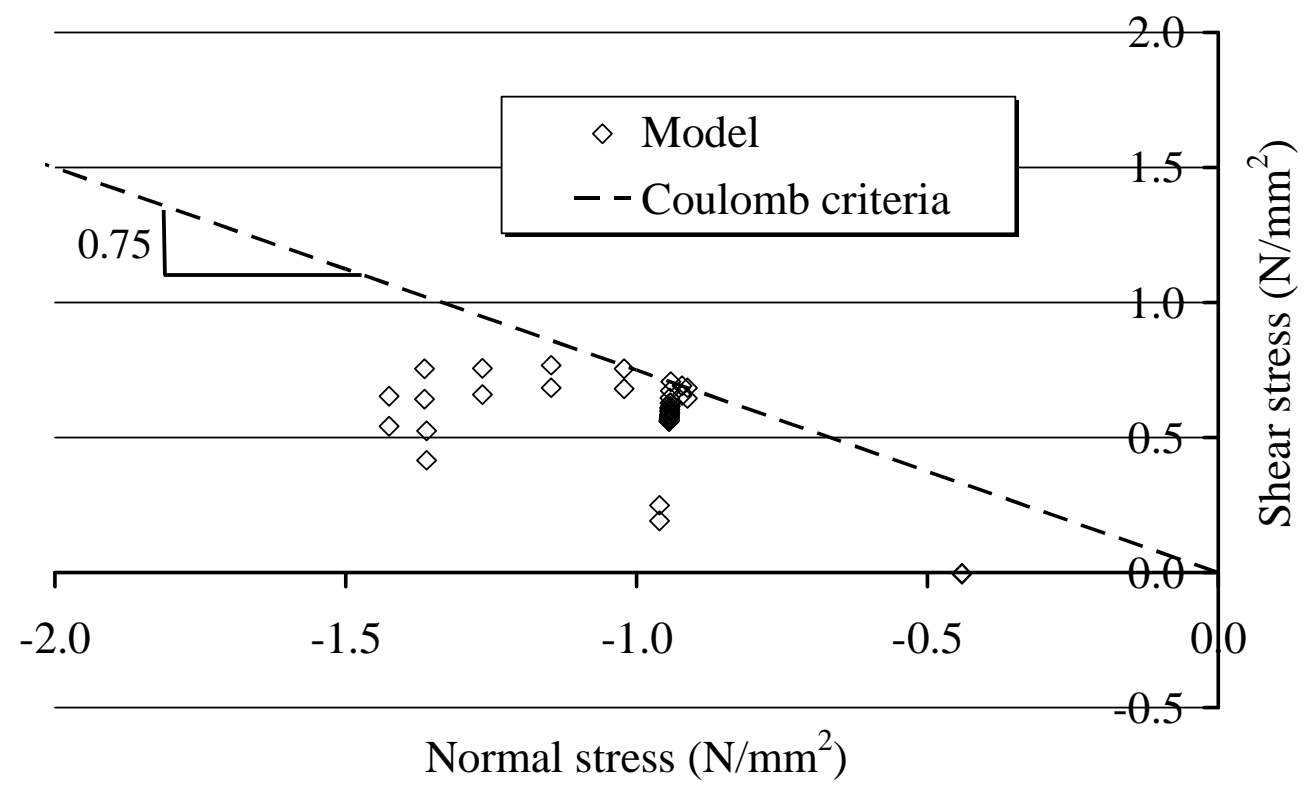

(b)

Figure 7 - Distribution of stresses in the joint: (a) normal and shear stresses; and (b) location of integration points with respect to the Coulomb failure criterion 


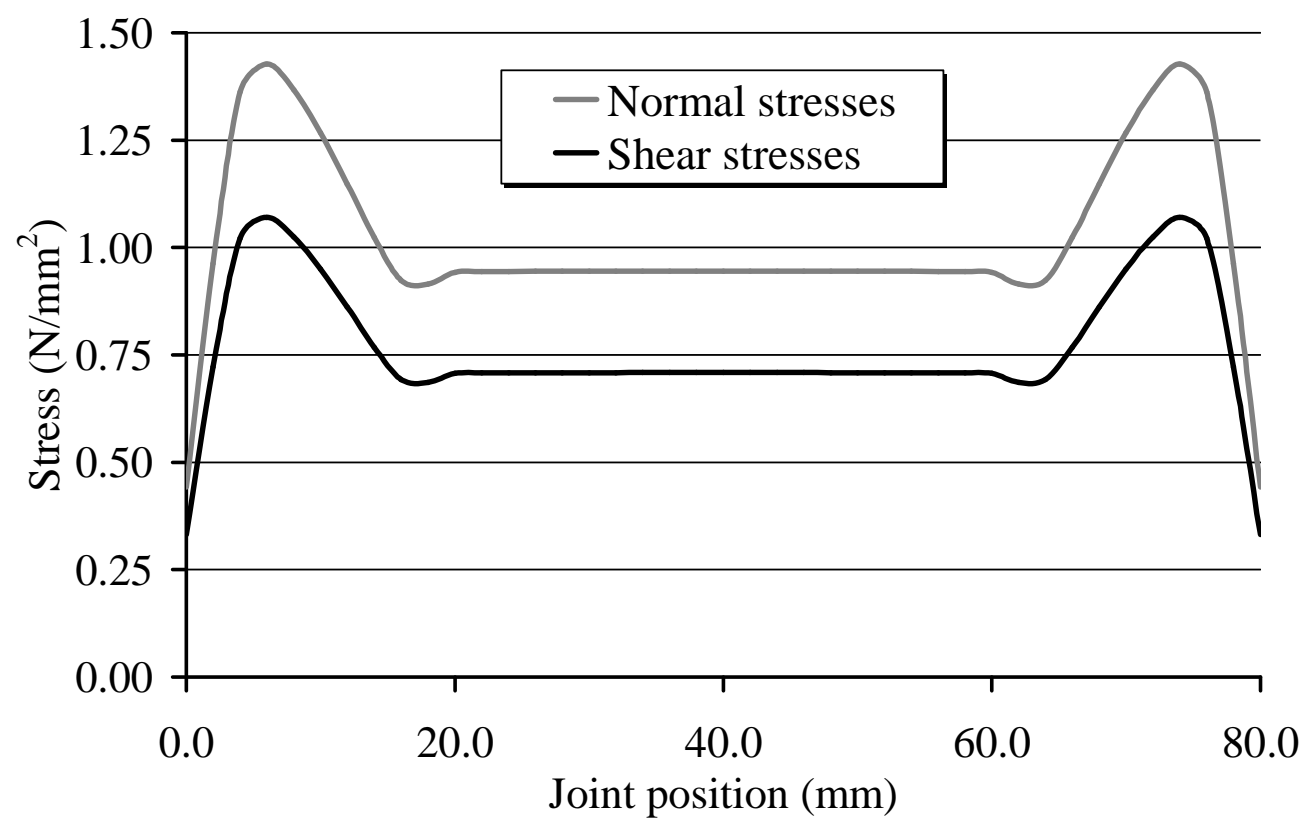

(a)

Figure 8 - Distribution of stresses in the joint after sliding: (a) normal and shear stresses; and (b) location of integration points with respect to the Coulomb failure criterion 


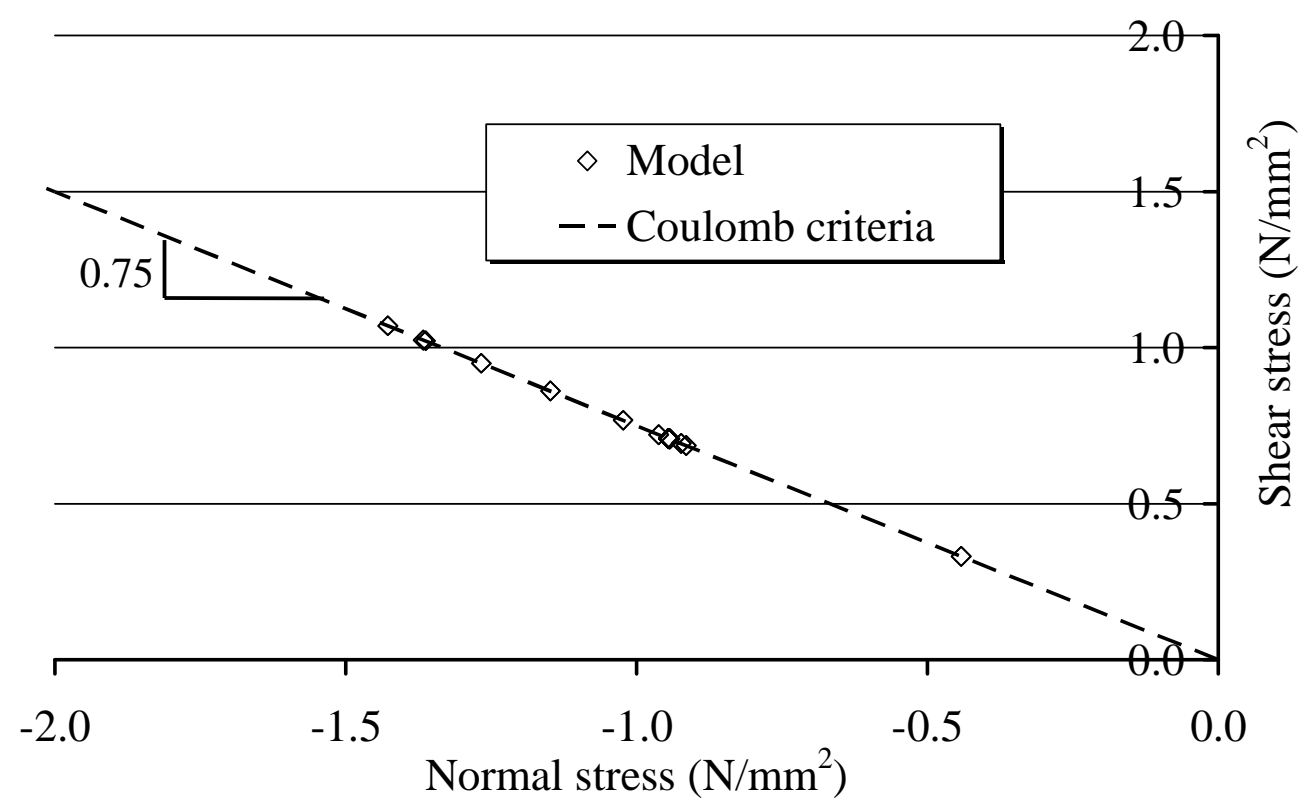

(b)

Figure 8 - Distribution of stresses in the joint after sliding: (a) normal and shear stresses; and (b) location of integration points with respect to the Coulomb failure criterion 


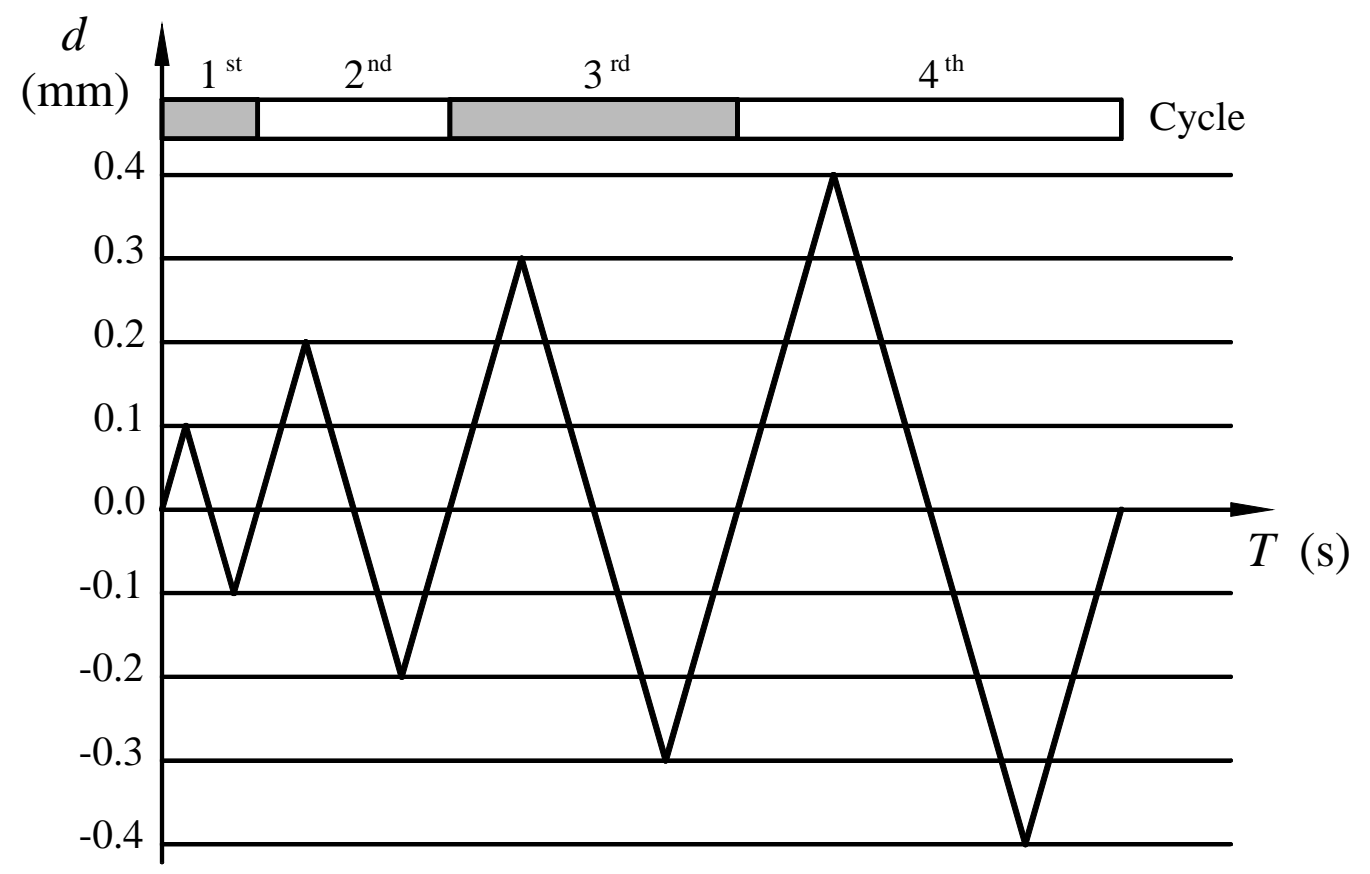

Figure 9 - Typical histogram for the prescribed horizontal displacements (series S) 


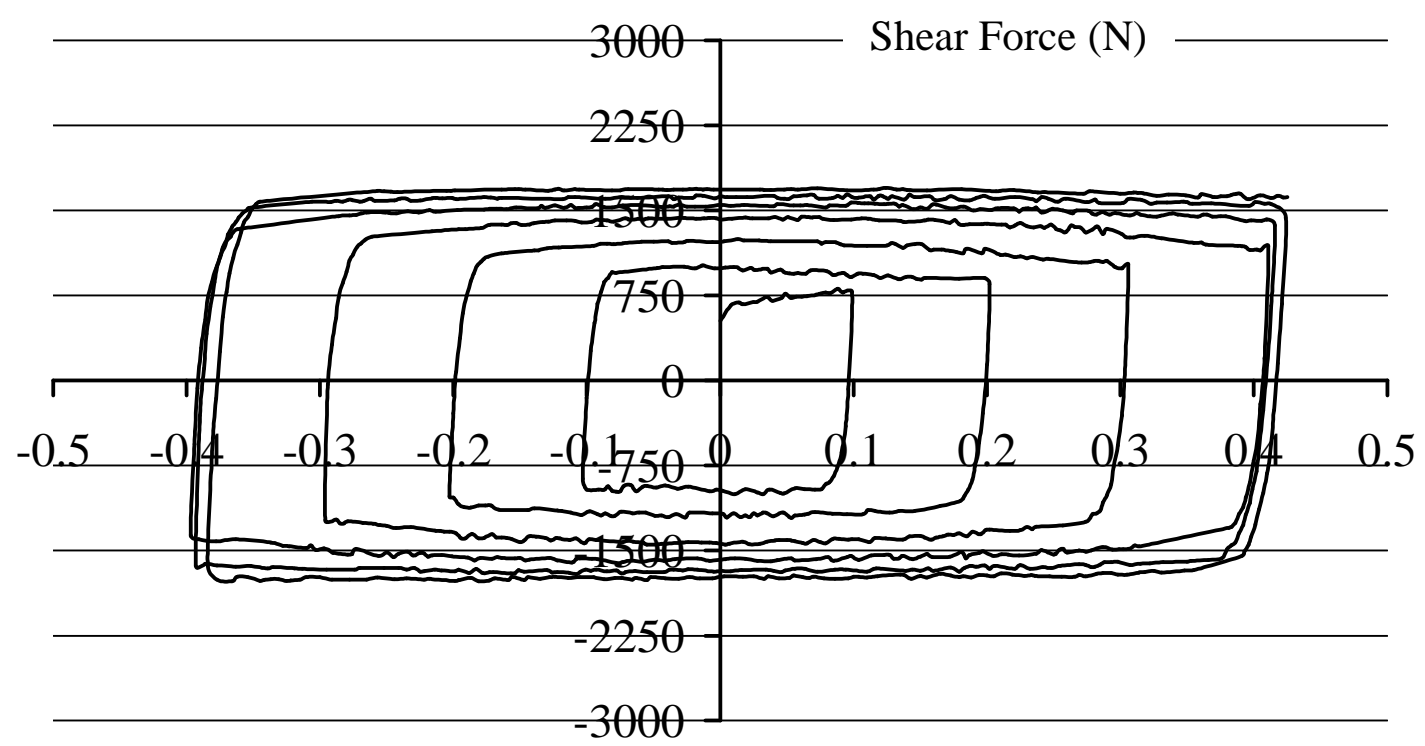

Horizontal displacement ( $\mathrm{mm}$ )

Figure 10 - Typical load-displacement diagram for a pre-confining level of $1.5 \mathrm{~N} / \mathrm{mm}^{2}$ (Series P) 


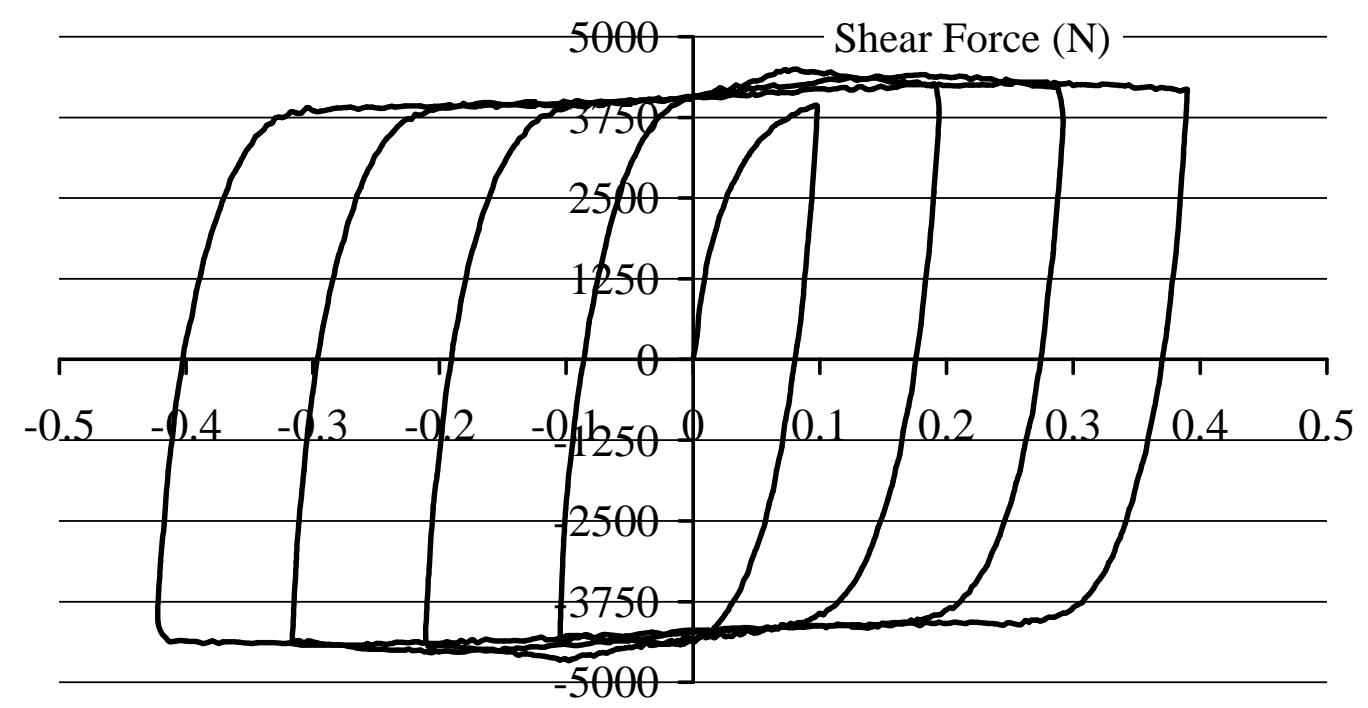

Horizontal displacement ( $\mathrm{mm})$

Figure 11 - Typical load-displacement diagram for a pre-confining level of $1.5 \mathrm{~N} / \mathrm{mm}^{2}$ (Series S) 


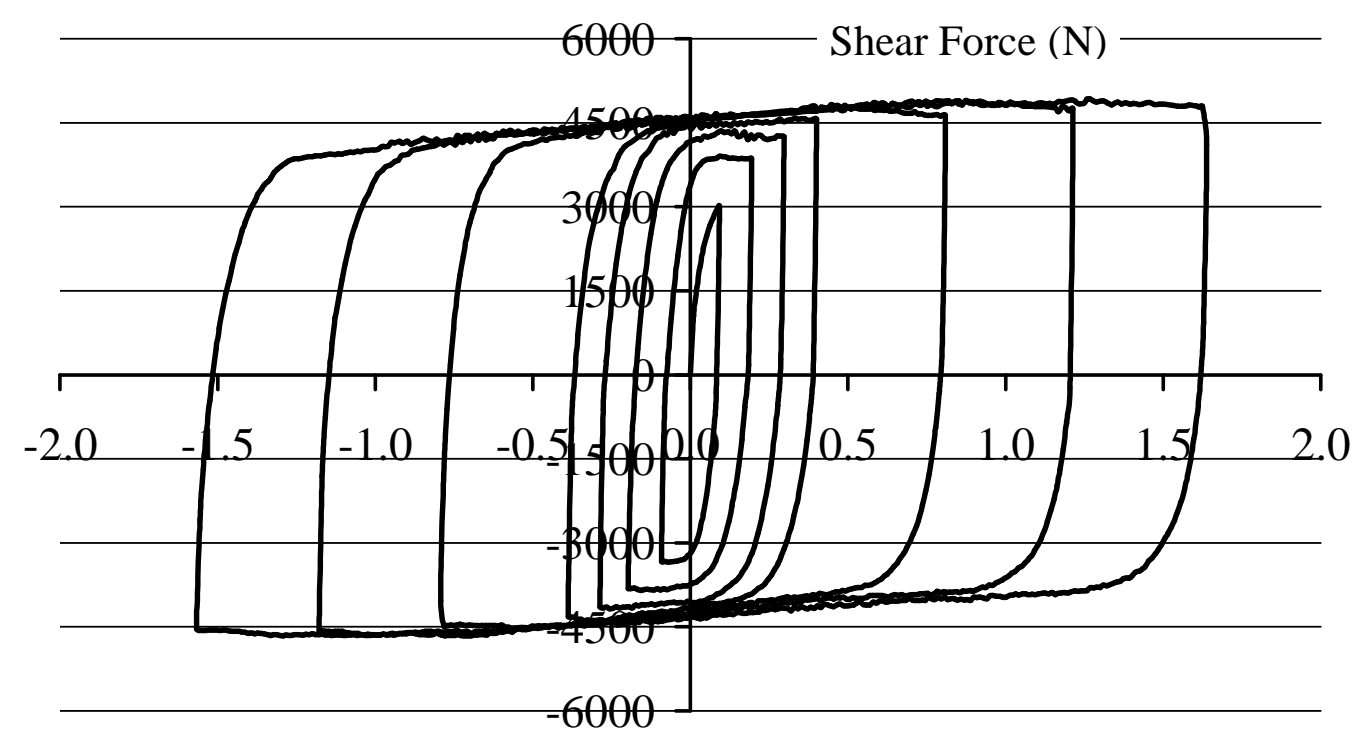

Horizontal displacement (mm)

Figure 12 - Typical load-displacement diagram for a pre-confining level of $1.5 \mathrm{~N} / \mathrm{mm}^{2}$ (Series R) 


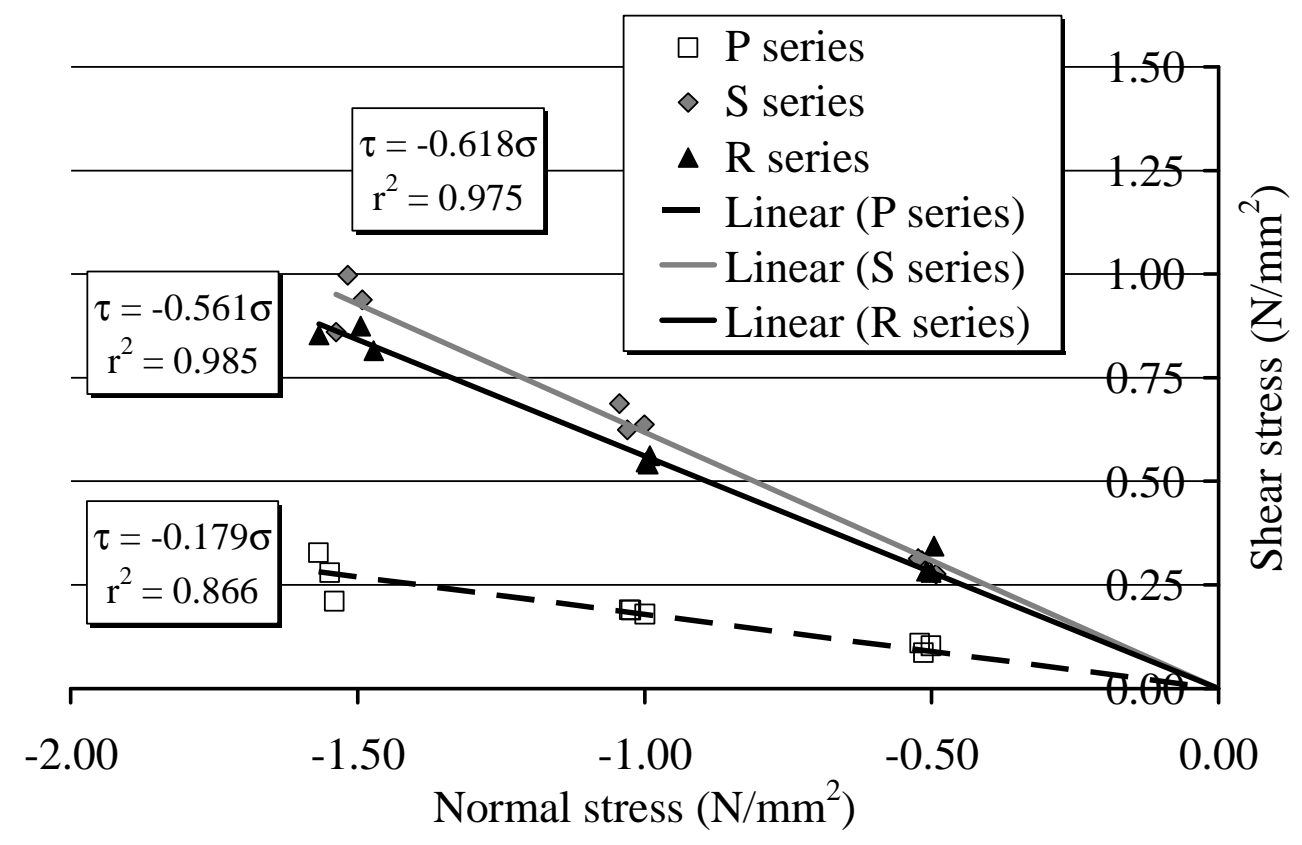

(a)

Figure 13 - Experimental failure criteria for different surface treatments: (a) initial failure criteria; and (b) final failure criteria 


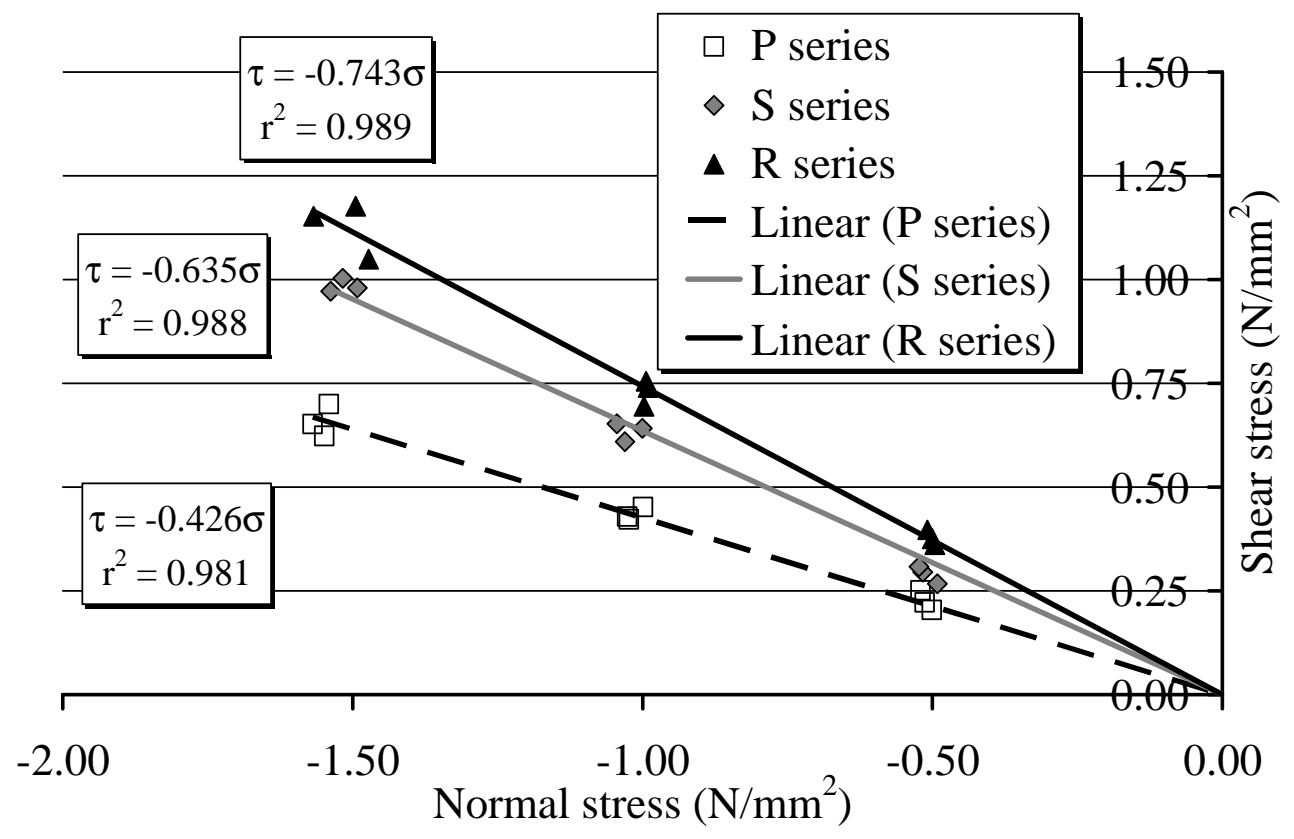

(b)

Figure 13 - Experimental failure criteria for different surface treatments: (a) initial failure criteria; and (b) final failure criteria 


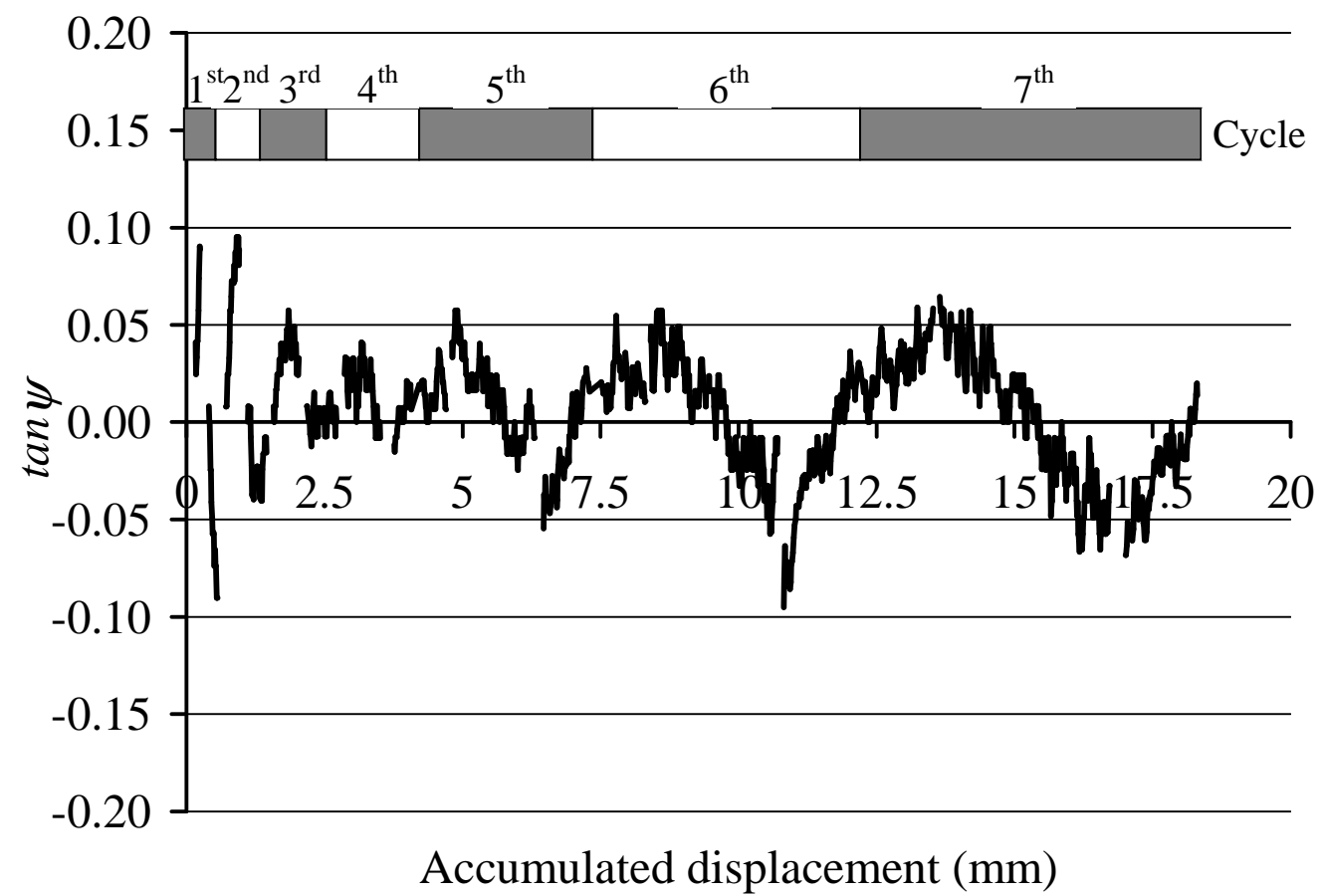

(a)

Figure 14 - Volume changes: (a) typical variation of the dilatancy angle; and (b) relation between horizontal and vertical displacements for all series 


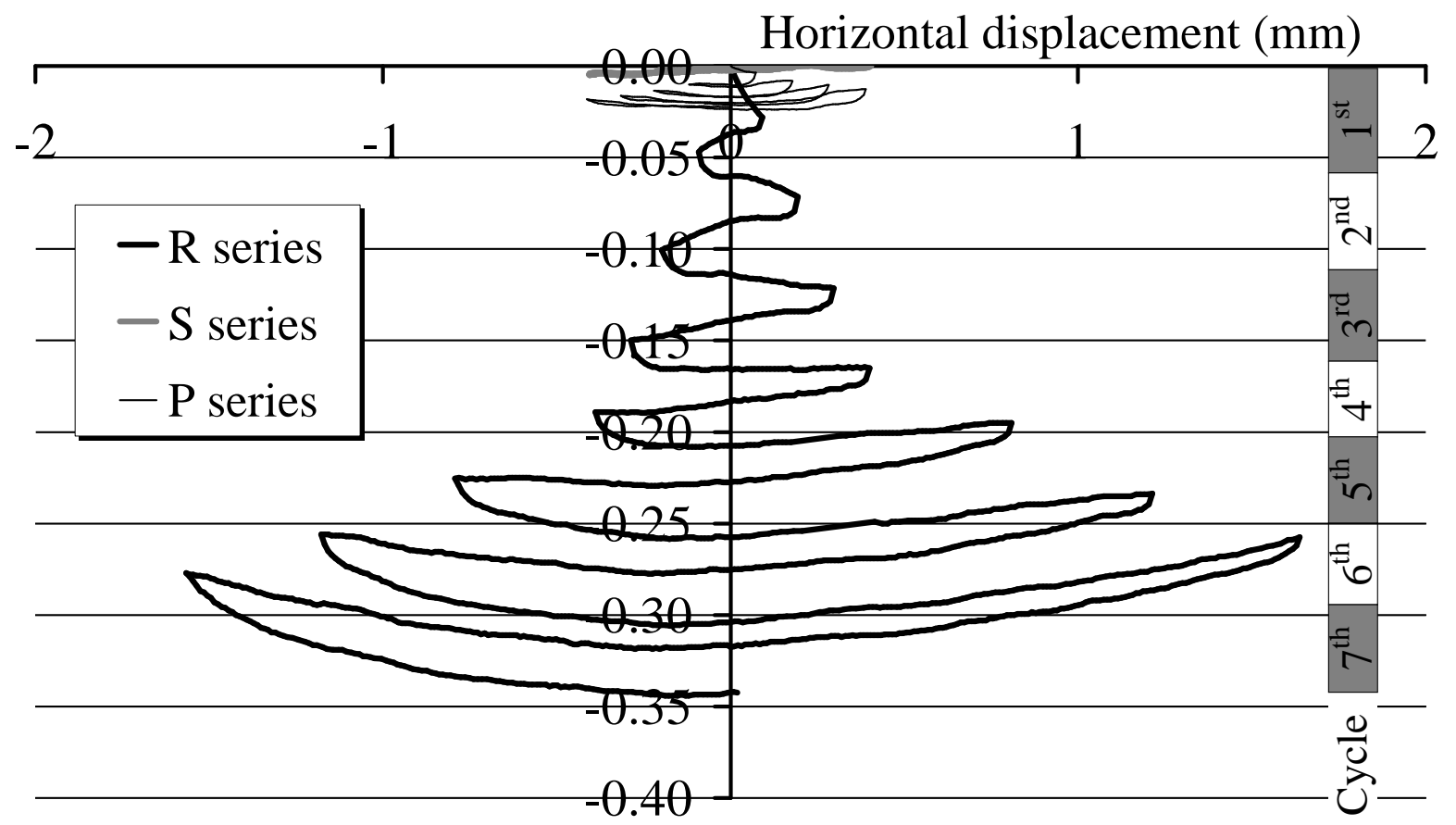

Vertical displacement (mm)

(b)

Figure 14 - Volume changes: (a) typical variation of the dilatancy angle; and (b) relation between horizontal and vertical displacements for all series 


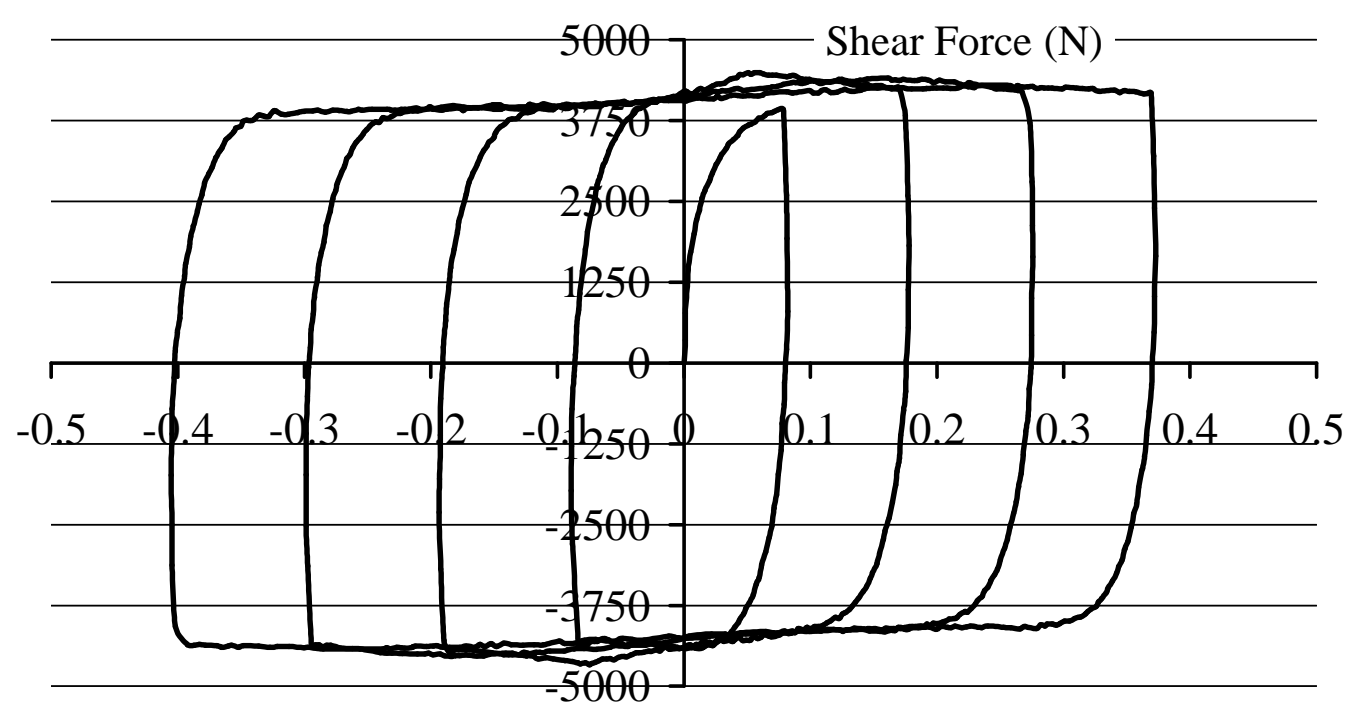

Horizontal displacement (mm)

Figure 15 - Typical adjusted load-displacement diagram for the joints of series $\mathrm{S}$ and $\mathrm{R}$ 


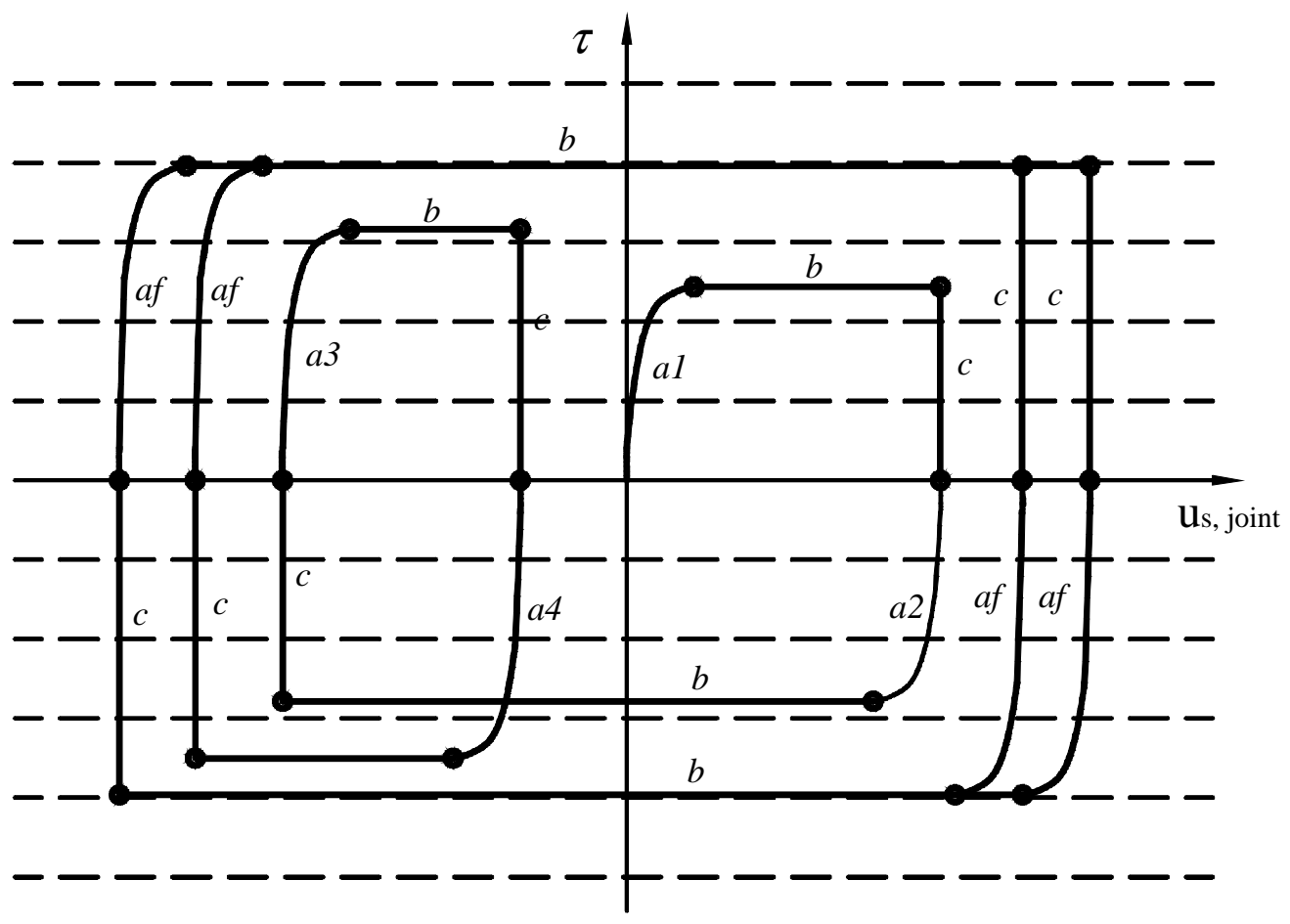

(a)

Figure 16 - Typical observed behavior of dry joints: (a) hysteretic diagram; and (b) failure criterion 


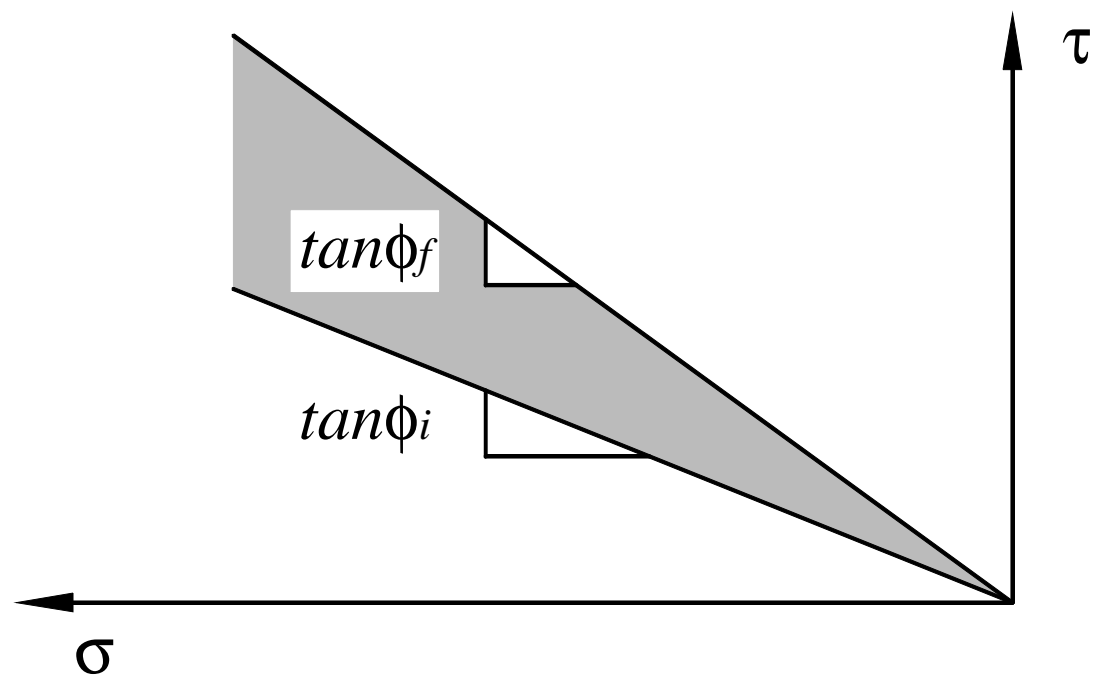

(b)

Figure 16 - Typical observed behavior of dry joints: (a) hysteretic diagram; and (b) failure criterion 